\title{
SIN DERECHO NI RAZÓN. SOBRE EL GARANTISMO PENAL DE L. FERRAJOLI: SU CARENCIA DE VALIDEZ CIENTÍFICA Y DE PRACTICIDAD REAL*
}

\author{
Minor E. Salas \\ Universidad de Costa Rica
}

RESUMEN. En este artículo quiero examinar, desde una óptica especialmente crítica y sin consideraciones a su amplia moda actual, algunas (no todas) las ideas centrales propuestas por L. FERRAJOLI con respecto a la doctrina del garantismo penal, tal como ésta se presenta básicamente en su obra Derecho y razón. Después de denunciar algunos vicios argumentativos -elementales, pero no por ello menos importantes- en que incurre el autor italiano, concluyo que las tesis centrales del llamado garantismo no aportan, en lo fundamental, nada sustancial al corpus del conocimiento que existe y que se conoce desde hace mucho tiempo sobre la materia penal. Al contrario, dicho garantismo resulta ser en la actualidad una ideología juridicista, no sólo engañadora sino acaso hasta dañina. Ella presenta el saber penal como si en este se tratara de una actividad primordialmente cognitiva y racional (científica), incluso susceptible de formalizaciones lógicas (por mor de algunas tablas «garantistas»). Así conduce a apartar la vista de las grandes líneas retóricas, vindicativas, poco racionales e incluso corruptas por las que desfilan, hoy como ayer, muchos de los casos penales que se resuelven en la práctica forense de los tribunales judiciales, especialmente en países como los de América Latina.

Palabras clave: FERRAJoli, garantismo penal, Derecho y razón.

ABSTRACT. In this paper I seek to examine, from a strictly critical point of view, some of the central ideas proposed by FERRAJOLI on the doctrine of criminal garantism, such as they are presented in Derecho y razón. After denouncing some argumentative mistakes made by the Italian author, I conclude that the main thesis of the so called garantism do not contribute anything substantial to the corpus of the existing knowledge on this subject. On the contrary, this garantism is at present a kind of «juridicist» ideology which is not only misleading but even harmful. This ideology presents criminal knowledge as if it were primarily a cognitive and rational (scientific) activity, even capable of logical formalization. In this way it leads one to ignore the main vindictive, rhetorical and scarcely rational and even corrupt trends that still today characterize many of the criminal cases that are resolved by the judiciary, particularly in Latin American countries.

Keywords: FERRAJOLI, criminal garantism, Derecho y razón.

Toda esa teoría no sirve más que para rebatirla.

LICHTENBERG

* Fecha de recepción: 14 de febrero de 2012. Fecha de aceptación: 28 de marzo de 2012. 


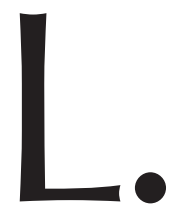

Ferrajoli (italiano, n. 1940-) es un autor que está de moda. Así lo demuestra su más reciente obra: Principia Iuris ${ }^{1}$, que ha pasado, poco tiempo después de su aparición, a formar parte de los libros más celebrados, con bombos y platillos, de Teoría del Derecho publicados en las últimas décadas. Ejemplo evidente de esto es también la aparición en la prestigiosa revista española Doxa de toda una sección, en la cual participa casi una veintena de autores de varios países, dedicada al examen y discusión de las tesis propuestas por FERRAJOLI en ese texto ${ }^{2}$. Allí, apenas iniciando esa sección y sin que se filtre el menor asomo de duda, un connotado jurista español declara, sin reserva alguna: ¡ «Soy creyente»! [...en FERRAJOLI]. Tal vez mi colega español haya lanzado tal afirmación a modo, simplemente, de una frase provocativa. ¡Pero no podría haber dado mejor en el clavo! En efecto, adherir a las tesis de nuestro autor no es, al fin de cuentas, sino una mera declaración de fe.

Ni más ni menos que de esa misma manera, justamente por ser recibida como una «verdad» de fe, vale decir, inmunizándose de antemano contra la posibilidad de hacerla objeto de unos análisis que no sean a priori «creyentes», es cómo la teoría del garantismo penal ha devenido —-desde la aparición en 1995 del libro de FERRAJOLI: Derecho y razón. Teoría del garantismo penal ${ }^{3}$ (amén de posteriores publicaciones suyas) - en una referencia usual y casi obligada para los más diversos círculos del derecho penal, especialmente en el ámbito de habla española. A partir de sus tesis ha surgido, en el campo penal y procesal penal, una acalorada disputa entre los partidarios de lo que se podría denominar, genéricamente y en el lenguaje ferrajoliano, como el modelo garantista (Il modello garantista), por un lado, y el modelo antigarantista (Il modello autoritario), por el otro.

Digámoslo sin preámbulo. En este trabajo pretendo refutar algunas de las ideas propias del modelo garantista, o cuando menos mostrar que son poco claras o triviales, y en todo caso inducen mucho más a error que a verdad. Esta afirmación es, sin duda, una pretensión que bien podría tomarse como arrogante de parte mía, en especial considerando que el profesor FERRAJOLI es un pensador internacionalmente reconocido. Mi única posibilidad de defensa, ante reparo tan contundente, es recordar que para el mundo intelectual no es lo más recomendable (¿estoy equivocado?) hacer de éste un concurso de fama, ni de títulos, ni de nacionalidades... ¡aunque para muchos parece que es así! Culto a unas personalidades — las que estén más de moda—. Sin embargo, para no «creyentes» —-todavía no está vedada del todo esta posibilidad—, a saber: pensar las cosas con la cabeza propia y examinar los problemas en sí, sin plegarse a ciertos prejuicios, gustos o preferencias que son moneda de circulación corriente en estos raros tiempos.

1 Principia iuris. Teoría del derecho y de la democracia, 1. Teoría del derecho, 2. Teoría de la democracia, 3. La sintaxis del derecho, trad. de P. Andrés IbÁÑEZ, J. C. BAyón, M. Gascón, L. Prieto SANChís y A. Ruiz Miguel, Madrid, Trotta, 2011.

2 Doxa 31, Cuadernos de Filosofía del Derecho, Seminario de Filosofía del Derecho de la Universidad de Alicante, Centro de Estudios Políticos y Constitucionales, Servicio de Publicaciones de la Universidad de Alicante, Alicante, España, 2008, 201-434.

3 L. FerRajoli, Derecho y razón. Teoría del garantismo penal, prólogo de N. BobBIo, trad. de P. ANDRÉs IBÁÑEZ et al., 3. ' ed., Madrid, Trotta, 1998. 


\section{PRESENTACIÓN DEL TEMA}

La discusión sobre el garantismo y el antigarantismo penal está dominada, en muchos casos y en el plano de las discusiones académicas actuales, por una alta dosis de generalidad, como también por no menos imprecisión y por mucha retórica. En ese debate no resulta inusual encontrarse, en uno y otro bando, afirmaciones tan disparatadas y contradictorias como las halladas en el siguiente catálogo (ejemplo paradigmático que me permito transcribir de un escrito publicado), el cual me parece de lo más representativo y sintomático de lo dicho:

- [...] El garantismo penal desprotege a las víctimas de los delitos.-Por culpa del garantismo penal los delincuentes cometen delitos libremente porque nunca serán sentenciados.-El garantismo penal y el abolicionismo penal significan lo mismo.-Los testigos del proceso son amenazados por culpa del garantismo penal._El crimen organizado se persigue debilitando el garantismo penal.-El garantismo penal impide la creación de nuevos delitos.-El garantismo penal está en contra de las penas de prisión.-El garantismo penal es causa de la impunidad.—El garantismo penal le hace daño a la sociedad ${ }^{4}$.

Frente a este catálogo de presuntos vicios o máculas, sugerido por parte de los detractores del garantismo penal, se le suele contraponer otro catálogo (no menos impreciso), esta vez por parte de sus defensores, que va más o menos en los siguientes términos:

[...] - [El garantismo] evita que personas inocentes sean víctimas de una condena injusta.- [E] garantismo no facilita la comisión de delitos y tampoco puede evitar la condenatoria de un (una) imputado(a) cuando las pruebas en su contra no dejan duda sobre su culpabilidad.-[El garantismo y el abolicionismo] son dos cosas distintas; el primero procura que se responsabilice a quienes delinquen, pero respetándoseles el debido proceso y su dignidad humana, en tanto el segundo aboga por desaparecer esa posibilidad.- [La amenaza de testigos] debe abordarse mejorando las formas de protección de testigos, sin que se recurra a propuestas que atenten contra las garantías del proceso.-Lo que resulta conveniente no es disminuir las garantías del proceso, sino mejorar la eficiencia en la investigación judicial, modernizando los recursos logísticos e intensificando la capacitación de los funcionarios.-[E]l garantismo procura evitar un crecimiento desmedido del derecho penal y que este asuma situaciones que bien pueden ser resueltas, eficientemente, por vías no penales o administrativas.-[El garantismo] procura que el derecho penal envíe a prisión sólo a quienes lesionan bienes jurídicos que son esenciales para la convivencia social, como — por ejemplo— la vida humana y otros más.—[L]as garantías fueron estatuidas sólo para el proceso penal; de manera tal que los problemas de inseguridad corresponde resolverlos sólo al Poder Ejecutivo.—[El garantismo] fortalece el Estado de Derecho ${ }^{5}$.

Por supuesto, y esto es esencial enfatizarlo, ni a FERRAJOLI ni a su teoría del garantismo, tal y como ésta se presenta en su libro Derecho y razón, le cabe responsabilidad alguna por las imprecisiones, confusiones o malentendidos que se generen en torno a un concepto («el garantismo penal») sobre el cual, en todo caso, aquel mismo no tiene - valga la expresión- el monopolio de su uso, ni tampoco el de la verdad de su contenido, a pesar de haber sido quien le dio la ciudadanía internacional en la discusión

4 Tomado de J. F. CAmpos C., «Mitos y falacias sobre el garantismo penal». En la dirección electrónica: http://wvw.nacion.com/ln_ee/2008/septiembre/09/opinion1694209.html.

${ }^{5} \mathrm{Id}$. 
académica. Sería absurdo, es más, una torpeza, sostener que cualquier disparate que se diga, aunque sea invocando el patrocinio conceptual de ese autor, ha de atribuírsele a la teoría garantista propuesta y defendida verdaderamente por su propia parte. Desde luego, yo estoy muy lejos de sostener semejante tontería.

Sin embargo, las contradicciones que afloran marcadamente en los párrafos transcritos sobre la categoría: «garantismo», ponen en evidencia algo que, desde mi punto de vista, es difícilmente refutable, a saber: la vasta multiplicidad de sentidos que se le pueden otorgar (y de hecho se le otorgan) a ese concepto, así como los muchos y contradictorios planos que allí salen a flote. No se trata, pues, de una categoría explicativa precisa, neutral, ajena a un discurso emotivizante e ideológicamente comprometido. Esta circunstancia, si bien constituye una apreciación elemental en el plano teorético, no deja de tener trascendencia a la luz de la laxitud metodológica, de la manipulación política y de la debilidad epistemológica que se infiltra en muchas de las discusiones que se gestan en este ámbito. Importa sacar a la luz que se trata de unas imposturas intelectuales (Sokal/Bricmont) cosechadas al calor de la moda actual del garantismo; pero no menos son tales también, por otro lado, las variadas acuñaciones terminológicas, no menos simplistas, que se le han contrapuesto desde otras veredas doctrinarias («derecho penal del ciudadano», «derecho penal del enemigo», etc.) ${ }^{6}$.

No pocas veces se provoca la impresión de que una obra como ésas a las que nos tiene acostumbrados FERRAJOLI — muy extensa y sistemática — requiere, para ser criticada auténticamente, enfrentarla mediante un despliegue teorético que necesitaría ser no menos extenso y sistemático. Tal consideración es de lo más errónea. Si uno quisiera criticar todos los aspectos de un libro como Derecho y razón, deteniéndose asimismo en todos y cada uno de los malentendidos que allí pueda haber, tendría que escribir no uno, ni dos, ni tres, sino muchos tomos iguales. Eso conduciría a la parálisis del pensamiento. Al final resultaría que, como es imposible examinar todo, no se critica nada. De ahí al dogmatismo, hasta el más cerrado imaginable, hay poco trecho. En mi caso, lo que examinaré son unas cuantas ideas asociadas a un único concepto: el de garantismo penal. Y al respecto, ni siquiera pretendo hacer un análisis pormenorizado de cada uno de los elementos que conforman esa categoría; he de referirme a cuestiones generales, pero no por ello menos importantes, en el abordaje que hace FERRAJOLI de dicha noción, así como a posibles consecuencias que de allí se derivan.

En síntesis: FERRAJOli es un pensador del derecho cuya obra se presenta como importante hoy día. Sus ideas y su doctrina sobre el garantismo penal circulan ampliamente en los ambientes intelectuales internacionales. Sin embargo, yo no he encontrado, hasta el momento, una valoración y crítica sustancial de esas ideas y de esa doctrina. Así es cómo tal «garantismo» ha terminado por convertirse en poco menos que un dogma en muchos círculos profesorales e incluso judiciales del derecho penal y procesal penal. Un dogma al que apelan, de manera poco clara y desinformada, muchas personas: abogados, jueces, profesores de derecho; de la derecha, de la izquierda, del centro - ...hay «creyentes» repartidos por todo el espectro político-. Dado ese amplio eco publicitario con que cuenta semejante ideología, me parece que bien vale

6 Para una discusión, vid. mi trabajo: «Ni Roxin ni Jakobs. ¿Necesita la dogmática jurídica otro repertorio más de fórmulas vacías?», estudio cuya publicación estoy tratando de lograr. 
la pena hacer ver sus falacias claves y en general las principales deficiencias de conceptuación que caracterizan a los dogmas fundamentales sobre los cuales se asienta esa doctrina globalmente. Eso sí, deslindemos bien nuestro tema. Lo advierto una vez más: este estudio se concentra sobre algunas de las ideas expuestas por FERRAJOLI. No voy a referirme a toda su obra - si es que tal cosa fuese en todo caso posible- ni siquiera a todos los aspectos contenidos en una de sus obras especializadas sobre la cuestión (Derecho y razón). Tampoco voy a exponer, con excesivo detalle, las clasificaciones y divisiones que incorpora el autor para ilustrar sus tesis básicas, especialmente en lo referente al campo del derecho constitucional y de los derechos fundamentales. Simplemente, voy a tomar unas cuantas de sus afirmaciones sobre el garantismo penal y examinarlas «en frío» (valga el término); es decir, tratando de no prejuzgar a priori si lo que allí se afirma es correcto, convincente o no. Es cierto que muchas de las ideas de ese autor (y él mismo lo ha reconocido) ${ }^{7}$ sobre el garantismo tienen vigencia en otros campos distintos al derecho penal, pero en este trabajo no exploraré las consecuencias que tengan esas ideas en esos otros campos, sino sólo en el ámbito jurídico-penal.

\section{HIPÓTESIS BÁSICAS A EXAMINAR (ADELANTADAS DE MODO AFORÍSTICO)}

[...] los conceptos viven su propia vida, y si no quieres arruinarte todas tus posibilidades de ingresar en este reino, no preguntes jamás a nadie para qué sirve todo esto que acá ves ${ }^{8}$.

Voy a postular primordialmente las siguientes hipótesis de trabajo, ciertamente provocativas. Ahora me limito a señalarlas muy aforísticamente; serán examinadas con mayor detenimiento a lo largo de este texto.

Primera Tesis: bajo el difuso concepto de garantismo caben (como ya se vio) muchas cosas. De allí que algunas precisiones básicas que se puedan hacer respecto a esa noción son, sin duda, pertinentes. Empero, la enorme cantidad de clasificaciones y divisiones por las que apuesta FERRAJOLI y, peor aún, la axiomatización de las tesis garantistas, representa simplemente una pedantería, un juego intelectual inútil. De lo que debiera tratarse, en cambio, es de ver si esas tesis tienen o no influencias, mayores o menores, en qué grados y de qué tipos, en los procesos penales concretos de un determinado ordenamiento jurídico. Lo del garantismo apunta, si bien se mira la cuestión,

7 Dice FERRAJOLI: «Más concretamente, la expresión "garantismo", en su sentido estricto de "garantismo penal", surgió, en la cultura jurídica italiana de izquierda en la segunda mitad de los años setenta, como respuesta teórica a la legislación y a la jurisdicción de emergencia que, por aquel entonces, redujeron de diferentes formas el ya de por sí débil sistema de garantías procesales... Por otro lado, a mi juicio, una concepción de este tipo del garantismo resulta extensible, como paradigma de la teoría general del derecho, a todo el campo de los derechos subjetivos, ya sean éstos patrimoniales o fundamentales, y a todo el conjunto de poderes, públicos o privados, estatales o internacionales». En el artículo: «Garantías», publicado en español en Jueces para la democracia, núm. 38, trad., del italiano de A. DE CABO y G. PISARELlo, Madrid, 2000, 39.

8 «...der Frobndienst der Begriffe, die anstatt, wie sie es beanspruchen können, sich selber zu leben, und wenn Du Dir die Aussicht auf Aufnabme nicht gänzlich abschneiden willst, so richte an Niemanden die Frage: wozu denn alles, was Du hier siehst, dienen solle. Dienen! Das fehlte noch, daß die Begriffe auch in unserm Himmel dienen sollten...» (R. v. JHERING, «Im juristischen Begriffshimmel», Parte III de Scherz und Ernst in der Jurisprudenz; arriba traducción parcial, según la versión de T. A. BANZHAF, en Bromas y veras en la Jurisprudencia, Buenos Aires, 1974). 
típicamente hacia lo que E. P. HABA denomina novela de conceptos ${ }^{9}$. En esa novela abundan categorías cuyo contenido no es descriptivo, como podría pensarse en un primer momento, sino básicamente emotivo y esencialista; o sea, eso son unas meras definiciones persuasivas (Ch. L. STEVENSON) que se utilizan para crear estados de ánimo y no para describir procesos conductuales reales de los agentes jurídicos.

Segunda Tesis: por principio, es posible formalizar lógico-simbólicamente toda suerte de referentes; al igual que es posible ponerse a contar y registrar con fines matemáticos — valga la imagen algo grosera — todos los granitos de arena que hay en una playa italiana. Sin embargo, la verdadera cuestión es esta otra: ¿para qué hacer eso? ¿Cuáles son los objetivos, teóricos o prácticos, que se quieren alcanzar? Pareciera que FERRAJOLI define y clasifica conceptos por el mero gusto de hacerlo, por una suerte de vis clasificatoria, a la cual se hará referencia luego. Por supuesto, siempre queda el recurso de reconocer simplemente que todo eso se hace con un interés puramente abstracto, del conocimiento por el conocimiento mismo. Ahora bien, ¿es eso lo que realmente quiere hacer FERRAJOLI con su teoría formalizada del garantismo? Pareciera que no. Allí se aspira a tener alguna utilidad práctica o, cuanto menos, teorética; pero entonces, ¿de qué tipo de utilidad estamos hablando? Todo esto provoca una confusión del plano puramente sintáctico-semántico con el pragmático.

Tercera Tesis: el aspecto realmente problemático en algunas de las tesis del garantismo penal no es tanto lo que ellas dicen (algunas ideas muy conocidas o incluso, lugares comunes), sino lo que no dicen. En efecto, ellas sirven sobre todo para apartar la vista de ciertos aspectos de la realidad forense: el carácter retórico del derecho, la sed de venganza sobre la que se basa el proceso penal en buena parte, la poca o ninguna sistematicidad del ordenamiento jurídico, las funciones simbólicas del derecho penal, la irracionalidad que está en la base de las actuaciones de las personas involucradas en un proceso judicial, la posible corrupción política y económica, etc. De tal manera se genera la impresión de que lo allí postulado encajará y mejorará sin más, y acaso hasta de una manera sistemática, la realidad judicial misma; cuestión ésta que está muy lejos, por supuesto, de poder cumplirse, y que se constituye en una mera «concepción misionera» acerca del jurista.

Cuarta Tesis: sostener — como lo hace FERRAJOLI en distintas partes de su obraque su sistema garantista es simplemente un modelo normativo o ideal basado en unos «axiomas básicos» es una estrategia de inmunización (H. ALBERT) para exorcizar la crítica. De esa forma, o sea, apelando a esos axiomas fundamentales del sistema (cuyo contenido está dado por unos «principios generales» que son suficientemente vagos e indeterminados) se garantiza que, frente a posibles objeciones sobre la funcionalidad empírica o sobre la plausibilidad judicial de su construcción logicista, la crítica sea despachada con la respuesta de que se trata, al final de la partida, de un modelo ideal que nunca se alcanzará de manera perfecta en la realidad, pues es «normativo». Surge así, únicamente que apertrechado con un carácter pseudo-analítico, un modelo que más que normativo es dogmático.

9 E. P. HABA, Metodología (realista) del derecho. Claves para el razonamiento jurídico de visión social prácti$c a$, t. II, párrafo 2. ${ }^{\circ}$ de la Sección G; Instituto de Investigaciones Jurídicas-Editorial Universidad de Costa Rica, San José (C. R.), 2011, 695 y ss., en prensa; texto amablemente facilitado por el propio autor. 
Quinta Tesis: con base en lo señalado (Tesis 1-4) resulta que las consideraciones de FERRAJOLI incurren en no pocos vicios y sofismas. A lo largo de este artículo serán examinados, entre ellos, los siguientes: partir, en la construcción de sus sistemas, de unas definiciones puramente persuasivas; asignarle valor de verdad a ciertas clasificaciones, las que por supuesto no pueden sino ser contingentes; otorgarle forma lógica a algunas ideas propias del lenguaje ordinario; otorgarle a ciertas definiciones estipulativas el carácter de definiciones esenciales; apelar a unos principios generales que operan como parapetos lingüísticos; definir lo desconocido por medio de lo desconocido; pasar por alto la distinción entre el nivel semántico y el nivel pragmático de las expresiones lingüísticas; presentar sus ideas personales bajo unos axiomas básicos que actúan como estrategias de inmunización.

Sexta Tesis: al fin de cuentas, las tesis centrales del garantismo penal propuestas por FERRAJOLI no aportan, en lo fundamental, nada sustancial al «corpus» de conocimiento que existe y se conoce desde hace mucho tiempo sobre la materia jurídico-penal; y, sobre todo, ellas no aportan elementos de juicio para discernir lo que sucede realmente en la vasta mayoría de los procesos penales reales. Semejante «garantismo» resulta ser principalmente un juego académico (repetimos: una novela de conceptos) que, empero, no se reconoce como tal. Así él se constituye en una ideología confusionista disfrazada, mediante la cual se aparta la mirada de los temas que tienen candencia real para determinar las prácticas del derecho penal contemporáneo.

Será necesario, desde luego, pasar a explorar más de cerca estas hipótesis de trabajo. Para ello voy a dar por conocidas las ideas principales de FERRAJOLI sobre la cuestión examinada, me bastará con recordar aforísticamente a cuál o cuáles de ellas me refiero de modo específico en mis pasajes correspondientes. Aquí las puedo muy bien «dar por conocidas», en efecto, pues entiendo dirigirme a admiradores de dicho autor, o en todo caso a quienes celebren estar bastante al tanto de sus planteamientos principales por considerarlos de señalada importancia. Es obvio que, en cambio, no seré yo quien recomiende sumergirse en dichos planteamientos a quienes no lo hayan hecho ya; en este último caso, por supuesto que no he de sugerirles dedicar tiempo tampoco a leer el presente trabajo (¿para qué emprender unos esfuerzos de curación si no se ha contraído la enfermedad? $\left.{ }^{10}\right)$.

[No obstante, por más superfluo, y no menos fastidioso, que lo considere yo mismo, no voy a eximirme de incluir una caracterización, aunque sea relativamente breve (en comparación con lo profuso de los párrafos que el autor dedica a especificarla), de cuanto el propio FERRAJOLI escribe para señalar qué entiende él por «garantismo» penal. Quien esté interesado en esos detalles, aunque nada decisivo incorporen a lo sustancial de cuanto será considerado en mis comentarios, hallará una serie de tales especificaciones suplementarias en el Apéndice ubicado al final del presente trabajo.]

10 En todo caso, como medida «profiláctica» (por así decir), si en algún momento estuvieren dispuestos a tomar contacto con escritos de dicho autor, tal vez no estaría de más que se tomaren la molestia de considerar las objeciones que serán planteadas aquí. 


\section{PRINCIPALES VICIOS EN QUE INCURRE FERRAJOLI}

Una vez efectuado el resumen precedente, corresponde abocarse a ver más de cerca los señalamientos críticos así adelantados. En este apartado retomaré una por una dichas Tesis para explicitarlas propiamente.

He aquí mi idea básica, bastante sencilla y hasta elemental: considero que FERRAJOLI ha logrado relativamente poco con su doctrina sobre el garantismo penal. Es más, me atrevo a decir que lo logrado por él mismo es básicamente dar una presentación diferente a ideas que eran ya de circulación corriente en numerosas obras de derecho penal y procesal penal. Detrás de su aparente rigorismo analítico se esconde en realidad una suerte de «escolástica descarriada de siglo» (para usar esta feliz expresión de C. VAZ FERREIRA), pues a fin de cuentas él nos viene a reiterar, si bien con otras palabras, unas tesis difundidas desde hace muchos años en el campo de la teoría del derecho y de la filosofía política. Digo todo esto sin ignorar, por supuesto, el gran esfuerzo académico que ha puesto el autor en la elaboración de toda su batería de definiciones y clasificaciones, como así también no dejo de reconocer que aquello puede tener un interés para algunas cosas y para algunas personas. Se trata, esencialmente, de un juego intelectual: ¡homo ludens!

En lo sucesivo quiero hacer notar algunas cuestiones muy básicas sobre por qué opino lo apuntado. No sin antes señalar (para evitar posibles suspicacias, second thoughts, como dicen en inglés) que yo no tengo el gusto de conocer personalmente al profesor FERRAJOLI, ni tampoco tengo nada en contra de él como persona; más bien, no dejo de experimentar cierta admiración, en cuanto a fortaleza de carácter, para el empeño de investigación, por el señalado esfuerzo personal y académico que vuelca en sus libros.

Los problemas o vicios argumentativos que yo veo en la concepción expuesta de FERRAJOLI sobre el garantismo son los que pasaré a exponer (el listado, por supuesto, tampoco es exhaustivo, sino meramente ejemplar).

\subsection{Partir - en la construcción de su sistema- de unas definiciones persuasivas (no rescatables para ningún discurso de exigencia científica)}

La pregunta clave que quiero hacerme, y que le ruego al lector tener en cuenta, es la siguiente: ¿Quién no se sentiría contento de que lo califiquen, o incluso calificarse a sí mismo, de «garantista»? O dicho de manera inversa: ¿a quién le gustaría que lo cataloguen como un «anti-garantista» («totalitario», «antidemocrático», o cualquier otro término similar)? Este interrogante no es inocente. Con él busco básicamente llamar la atención sobre el hecho, a veces olvidado, de que la mera alusión a una «teoría general del garantismo» se convierte, a pesar o posiblemente incluso en contra de la intención de su creador, en una definición persuasiva. Voy a entender por definición persuasiva, de la mano de STEVENSON, aquella donde el concepto, a pesar de poseer un significado parcialmente descriptivo, lo que impone es su significado emotivo. El propósito de la definición [persuasiva] es cambiar el significado descriptivo del término para otorgarle, usualmente, una mayor precisión dentro de los limites de su vaguedad. Pero la definición 
no produce ningún cambio fundamental en el significado emotivo del término. Y es usa$d a$, consciente o inconscientemente, para lograr que las actitudes de la gente cambien, dado el juego que existe entre el significado emotivo y el descriptivo ${ }^{11}$.

Con lo anterior quiero señalar que, si bien no se puede negar que un concepto como el de «garantismo» tenga también una dimensión descriptiva, como concepto técnico dentro de una determinada doctrina; sin embargo, aquí el elemento descriptivo, que es el favorecido muchas veces por el autor, cede ante el elemento emotivo (el cual, dicho sea de paso, puede ser independiente de las intenciones mismas del autor). Evidentemente, uno puede asociar, de hecho, la palabra «garantismo» con principio de legalidad, con legitimidad en sentido material, con validez, etc.; proceder así en un nivel lógico-semántico, de descripción de aquellos elementos que estimamos como formando parte de la definición descriptiva del concepto de garantismo. No obstante, psicológicamente esos elementos son, o pueden ser, traídos a colación para cambiar la valoración que una persona tenga de ese concepto. Expresado en términos técnicos: la denotación de la palabra garantismo puede estar conformada por unos elementos descriptivos; sin embargo, su connotación está sujeta a la valoración o incluso a la percepción emocional de quien escucha la palabra. Este hecho, muy básico, convierte la noción de garantismo en un término-bandera ${ }^{12}$, un instrumento al servicio de las emociones. Con ello lo torna muy poco propicio para efectos científicos.

\subsection{Falsa precisión; asignar validez a título de verdad para unas clasificaciones contingentes}

- [...] ¿Y esta máquina tan extraña?

- Es una partidora de pelos*. Cuando rindas tu examen de derecho deberás dividir con ella un cabello en 999.999 partículas... Es verdaderamente increíble cómo el ojo se va perfeccionando y cómo crece con la práctica el virtuosismo en el arte de partir pelos. Tenemos aquí algunos juristas capaces de dividir cada una de esas partículas en otras 999.999 fracciones ${ }^{13}$.

Un hábito intelectual — por cierto muy pertinente en el campo de la filosofía analítica (cuando no se recurre a él para unos efectos de mera pedantería) — es precisar y definir los conceptos empleados en una discusión. Recuérdese, en este sentido, la máxima de CONFUCIO: «Cuando el lenguaje no concuerda, entonces todo aquello que se dice, se transforma en todo aquello que NO se intentó decir...» ${ }^{14}$. Pocas cosas hay

11 Ch. L. Stevenson, Ética y lenguaje, trad. de E. A. Rabosi, Barcelona, Paidós Studio, 1984, 198.

12 «La palabra misma puede convertirse en una bandera, un símbolo de todo lo que es caro al hombre, de todo lo que ama en su nación, ya sea racionalmente contingente a la misma o no» (J. SCHUMPETER, Capitalismo, socialismo y democracia, cap. XXI, párr. IV). Cfr. E. P. HABA, «Retórica de "la" Libertad contra las libertades», Revista de Ciencias Jurídicas, núm. 75 (mayo-agosto 1993), 113-158, Universidad de Costa Rica; vid. especialmente su apartado IV, donde el pasaje transcrito se encuentra en la p. 129, nota 6a.

* N. del T.: Haarspaltemaschine: máquina-partidora-de pelos [partir pelos (verticalmente) tiene en alemán, en sentido figurado, el significado de nimia escrupulosidad, meticulosidad excesiva].

${ }_{13}$ «Das ist die Haarspaltemaschine. Es ist unglaublich, wie das Auge sich ausbildet, und wie die Virtuosität im Haarspalten durch die Übung wächst» [JHERING, op cit. (en la nota 9); pasaje correspondiente a la p. 202 de la mencionada traducción].

${ }^{14}$ Citado en B. RüTHERS, Teoría del derecho. Concepto, validez y aplicación del derecho, trad. del alemán de M. E. Salas, México D. F., Ubijus, 2009, 85. 
tan dramáticas, y acaso tristes, como ver a dos pensadores de la teoría del derecho debatir interminablemente por la naturaleza de un instituto jurídico, sobre su «esencia» o sobre su significado «real». Por eso, repito, es muy conveniente utilizar las palabras de acuerdo con unos sentidos previamente estipulados, para evitar de esta manera confusiones y disputas innecesarias. De ahí, la recomendación de VAz FERREIRA: «Del mismo modo que los cirujanos no emprenden una operación sin desinfectar previamente todos los útiles que se proponen usar, nadie debería emprender un raciocinio sin haber dejado de antemano todas las palabras que va a emplear, completamente asépticas de equívocos» ${ }^{15}$.

Hasta aquí, todo en orden. Pues bien, ¿no se trata justamente de un empeño de tal naturaleza en nuestro autor, un denodado esfuerzo suyo por precisar conceptos jurídicos fundamentales? ¿No es justamente ése el alfa y omega de la gran minuciosidad doctrinaria en que se embarca FERRAJOLI? Sí... ipero no! Me explico: también se presentan contextos de examen en donde, por la manera propia en que son desarrollados específicamente ciertos análisis, el resultado verdadero de éstos es que allí la propia claridad y el afán por la precisión pasan a ser convertidos en unos obstáculos epistemológicos (G. BACHELARD) para el pensamiento. Así es también cuando el inusitado exceso de precisiones (supuestas) «enreda» hasta tal punto el asunto considerado, que se termina perdiendo de vista el o los problemas «vitales» por resolver. Entonces ese cúmulo de precisiones no pueden ser ya en un medio para conocer mejor la realidad, sino que se constituyen antes bien en un denso enjambre de capas de encubrimientos frente a esta misma. La multiplicación de definiciones y clasificaciones pasa a constituirse, de hecho, en el fin de tales tipos de actividad discursiva, en cuanto esta es desempeñada así. Lo de FerRAJOl constituye un ejemplo muy neto de tal tipo de discursos. Basta leer con atención algunos capítulos de su obra para observar cómo afloran allí una innumerable cantidad de clasificaciones y múltiples precisiones conceptuales que, después de cierto nivel, no aportan mayor cosa al esclarecimiento de los asuntos tratados. Más bien ellas tienden a embrollar el panorama, su exposición se transforma en una espesa selva donde acechan toda suerte de fieras y alimañas, que son meramente conceptuales.

Cuando se lee la obra de FERRAJOLI, y en específico su desarrollo sobre la teoría del garantismo, se tiene una experiencia bastante ambigua. A primera vista, uno siente como si el autor le está transmitiendo algo necesariamente profundo; en especial porque él trata de definir con mucho detalle los conceptos que emplea y, además, porque cuidadosamente va realizando una clasificación tras otra. Entonces, la primera impresión es que aquello que él nos dice, al ser formulado de una manera tan meticulosa, ha de ser verdadero. Y acá está precisamente el error. Si se continúa con una lectura atenta, luego uno verá cómo todo eso que en un primer momento aparecía como preciso, en realidad se va tornando más y más oscuro y confuso. Después de unas cuantas páginas, el lector ya se ha olvidado de qué es verdaderamente lo que se venía discutiendo; todos los esfuerzos van ahora encaminados a conseguir aprehender un abrumador cúmulo de detalles, un mar de sutilezas lingüísticas acerca de las cuales se da por sobreentendido que puedan servir de algo en la práctica.

15 C. Vaz Ferreira, Fermentario, Homenaje de la Cámara de Representantes de la República Oriental del Uruguay, vol. X, Montevideo, 1963 (ed. or. 1938), 239 pp. 
Se presenta así un fenómeno que podría llamarse, junto con C. VAZ FERREIRA, el sofisma de falsa precisión. Él supo advertirlo hace ya un siglo. Y recuérdese que ese pensador justamente, es el autor de la cita sobre necesidad de precisión recogida un poco más atrás: «Del mismo modo que los cirujanos...». No obstante, ni más ni menos que a él mismo no se le escapó tampoco que:

El espíritu humano desea la precisión en el conocimiento, y se satisface con ella. La precisión es buena; es el ideal, cuando es legítima; pero en cambio, cuando es ilegítima o falsa, produce, desde el punto de vista del conocimiento, efectos funestos: oculta hechos, desfigura o falsea interpretaciones, detiene la investigación, inhibe la profundización; sus resultados perjudicialísimos, pueden condensarse fundamentalmente con estos dos adjetivos: falseantes e inhibitorios ${ }^{16}$.

Yo creo que esta vis clasificatoria — para usar una expresión bien gráfica- de FERRAJOLI, sobre la que se monta una buena parte de la estrategia metodológica en su obra, obedece, si eso se examina con cuidado, a una pretensión de «cientificidad» que es apenas ilusoria. Esta consiste, a fin de cuentas, en unos mecanismos mentales de Haarspaltemaschine (máquina-partidora-de-pelos), similarmente a como lo había advertido JHERING hace un siglo y medio. Aun haciendo abstracción de lo vano que es desviar la mente hacia el horizonte de tamaña colección de detallismos, resulta que, después de todo, ellos no sólo son superfluamente pedantes, sino que, bien mirados, en el fondo vienen a ser, como señaló VAZ FERREIRA, esencialmente falseantes e inhibitorios. Es cierto, por supuesto, que en un lenguaje científico cuanto más unívocos, exactos, limitados se encuentren los términos que utilizamos, menor es el riesgo de equivocarnos o de confundir los fenómenos. No obstante, todo depende del contexto y de la necesidad real que exista de contar con esa exactitud específica; así, en su caso, la conveniencia práctica de realizar ciertas clasificaciones, para guiar nuestro pensamiento con vistas a lograr unos resultados que no se alcanzarían de otras maneras (eventualmente más cómodas). La idea fundamental a tener en cuenta aquí es la siguiente: la simple presencia de precisión en la presentación discursiva de unos X o Y asuntos (en especial cuando esos asuntos se refieren a la experiencia humana), la simple presencia de unas definiciones estipulativas o de unas clasificaciones muy detalladas y con apariencia muy exacta, no garantizan, ni remotamente, que lo que se diga allí sea verdad; más aún, ni siquiera permiten asegurar, tampoco, que lo así presentado sea «correcto» desde algún punto de vista sustancial valorativo.

En nuestro medio, donde se rinde a veces un culto desmesurado a la presentación matemática o lógica de las ideas, la formulación en esos términos resulta especialmente atractiva y es una verdadera tentación para muchos autores, quienes procuran así darle una apariencia especialmente rigurosa y científica a sus textos. Quizás nadie mejor que el conocido sociólogo S. ANDRESKI logró percibir netamente esta circunstancia:

«El punto básico reside en que no pueden convertirse generalizaciones vagas y dudosas (y no digamos disparates e inanidades) en una ciencia matemática [o lógica] mediante el simple expediente de transcribirlas en el simbolismo de las matemáticas [o de la lógica]». Y continúa en otro sitio señalando: «La mayor parte de las aplicaciones de las matemáticas [o de la lógica] a las ciencias sociales, al margen de la economía, pertenecen al tipo de innovaciones rituales que han creado su propio estilo de hechicero. La receta para ingresar como

${ }^{16}$ C. VAz FerReIRA, Lógica viva (adaptación práctica y didáctica), 2. ed., Buenos Aires, Losada, 1952, 83. 
autor en esta línea de negocios es tan simple como remunerativa: tómese un libro elemental de matemáticas [o de lógica], comience con las partes menos complicadas, añádanse a la literatura en una o dos ramas de las ciencias sociales sin preocuparse excesivamente acerca de si las fórmulas escritas tienen alguna relación con las acciones humanas reales y póngasele al producto un título sonoro [Derecho y razón... Principia Iuris], insinuativo de que se ha encontrado una clave para una ciencia exacta de la conducta colectiva ${ }^{17}$.

En definitiva: la verdadera cuestión, de la cual FERRAJOLI no parece tomar nota, no está en establecer una gran lista de definiciones para los conceptos que utilizamos ni tampoco en clasificarlos según unos refinadísimos criterios, cada uno de los cuales bien pueden resultar o no interesantes (según los gustos de cada quien), sino más bien en ver cómo esas definiciones o clasificaciones consigan verdaderamente aclarar, modificar en la práctica o explicar científicamente aspectos de la realidad que no es posible resolver adecuadamente de otra manera. Asimismo, no es cuestión de pasar por alto que esas clasificaciones no poseen un valor de verdad; no existen clasificaciones que resulten ni más ni menos verdaderas que otras. Es fundamental no perder de vista lo que hace ya tiempo señaló, de manera inusualmente sensata, G. R. CARRIÓ:

Los juristas creen que esas clasificaciones constituyen la verdadera forma de agrupar las reglas y los fenómenos, en lugar de ver en ellas simples instrumentos para una mejor comprensión de éstos. Los fenómenos — se cree- deben acomodarse a las clasificaciones y no a la inversa. Buena parte de las controversias entre juristas consisten en problemas de clasificación, abordados como si se tratara de cuestiones de hecho. No se advierte que no tiene sentido refutar como falsa una clasificación —o sus resultados- y postular en su reemplazo otra «verdadera»... Las clasificaciones no son ni verdaderas ni falsas, son serviciales o inútiles; sus ventajas o desventajas están supeditadas al interés que guía a quien las formula, y a su fecundidad para presentar un campo de conocimiento de una manera más fácilmente comprensible o más rica en consecuencias prácticas deseables ${ }^{18}$.

\subsection{Disimular bajo unas máscaras logicistas («falacia de la forma lógica») lo que no son sino unas ideas del pensamiento vulgar}

Digámoslo sin reserva. Es posible darle — si uno se lo propone- a cualquier disparate, e incluso a un absurdo, una forma estrictamente lógica. ¡La lógica formal (i. e., la simbolización) es — valga el símil algo poético- como una plastilina en las manos de un niño travieso y juguetón! (en este caso, es FERRAJOLI). Las verdaderas preguntas aquí no son si una notación lógica, por ejemplo, de los axiomas fundamentales del garantismo es o no es viable, sino con qué propósito se va a realizar dicha notación, con qué objetivo en la mente. ¿Para qué se quiere hacer eso? Tomemos como ejemplo a examinar la simbolización efectuada por FERRAJOLI de los diez principios básicos de su teoría. Según sus propias palabras, el sistema garantista puede expresarse mediante la siguiente notación lógica:

$$
\begin{aligned}
& \text { T56 (PE } \rightarrow \text { [DE.LP.NE.IN.AT.CU.JU.AC.PR.DF]) } \\
& \text { T57 (DE } \rightarrow \text { [LE.NE.IN.AT.CU.JU.AC.PR.DF]) } \\
& \text { T58 (LE } \rightarrow \text { [NE.IN.AT.CU.JU.AC.PR.DF]) }
\end{aligned}
$$

17 S. ANDRESKI, Las ciencias sociales como forma de brujería, trad, de A. DEUTSCH, Madrid, Taurus, 1972, $159-160$

18 G. R. Carrió, Notas sobre derecho y lenguaje, 4. a ed., Buenos Aires, Abeledo-Perrot, 1994, 99. 


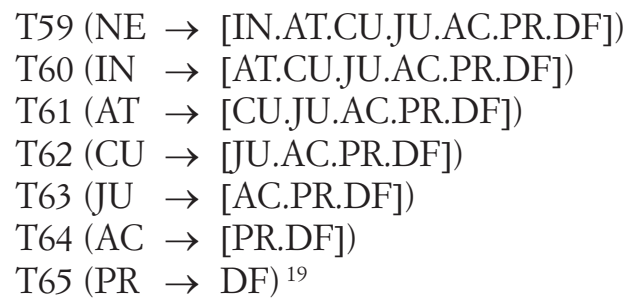

No dudo que esta forma de presentar los principios garantistas sea lógicamente correcta, en cuanto posibilidad formal de presentación (una posible en ese plano). Tampoco pongo en tela de duda que ello represente un ejercicio mental capaz de resultarle interesante, acaso hasta entretenido, para algunas personas dedicadas a ese campo de estudio. Sin embargo, no creo que la pretensión de FERRAJOLI (a pesar de ser normativa) sea puramente de interés académico, de entretenimiento o lúdico. Entiendo que no se trata ahí de un conocimiento perseguido por el conocimiento mismo, ¡sin más! Una suerte de arte por el arte (l'art pour l'art). Después de todo, o mejor dicho, antes de todo y más que todo hay allí una aspiración —una «expectativa», como diría él— de funcionalidad para su modelo con vistas a aplicarlo en un ordenamiento jurídico determinado. En fin, yo pienso que FERRAJOLI quiere que su teoría sea útil para la justicia penal de este mundo, servirle a personas de carne y hueso. Desde esta óptica, cabe preguntarse qué aspectos de la realidad jurídica, ya sea de los procedimientos judiciales tal como funcionan de hecho o de sus consecuencias sociales, se logra acaso entender de una mejor manera con esta simbolización que sin ella. La cuestión es averiguar qué aporte, en el plano del conocimiento pero sobre todo de la pragmática judicial, se haya logrado con elaborar la anterior tabla de axiomas. En fin, ¿'en qué ayuda verdaderamente esa tabla, u otras por el estilo, digamos a un juez que desea tomar una decisión más garantista en comparación con otro juez que no la usa? Ésta es una pregunta de hecho que, en todo caso, debiera probar quien propone la simbolización.

A mí me da la impresión de que formalizar en notación lógica una teoría del derecho penal es, más que nada, mera pedantería. Al menos lo es en el plano judicial. Obra solamente para efectos lúdico-académicos. Consiste, si bien se mira, esencialmente en una criatura más del «espíritu de geometría» (PASCAL), en este caso para entretener sobre todo a profesores de derecho penal o especializados en Teoría del derecho. Digo, se trata sustancialmente de unos juegos de pedantería profesoral, sobre todo en virtud de tres consideraciones fundamentales. Primera: no todas las personas (ni siquiera la mayoría) de quienes se dedican a aplicar el derecho, por ejemplo, los jueces o los fiscales, conocen la lógica formal o simbólica al punto de poder valorar si las tablas propuestas por FERRAJOLI cumplen o no con principios de inferencia, de validez, de consistencia, etc., requeridos en dicho campo de investigaciones. Segunda: y resulta que además, por añadidura, es muy poco probable que esa simbolización permita realmente salvaguardar los derechos de una persona a quien se le está violando una cierta garantía judicial; ni tampoco comprender mejor esa garantía, aunque sea en el plano teorético-explicativo. Tercera: no veo qué posible desarrollo se logre, ya en el plano teorético, traduciendo proposiciones del lenguaje ordinario a un lenguaje sim-

19 L. FerRajoli, Derecho y razón, 112. 
bólico - ¿se obtiene con ello algún avance para lo que es conocimiento mismo?-. En cuanto a esto último ha dicho HABA, con mucha razón, aunque quizás con excesivo énfasis:

Pero cabe reconocer que aun esas logificaciones de ALEXY resultan algo así como un juego de niños, todavía no demasiado lejano con respecto a las «travesuras» de los operadores jurídicos reales, si aquellas venimos a compararlas con unos extremos tan infinitamente ajenos al pensamiento de estos mismos como esa vía láctea de axiomatizaciones que conforman el divertimento extraempírico mayor propuesto por L. FERRAJOLI para entretener a profesores de Teoría del Derecho... ${ }^{20}$.

Por lo demás, la presentación lógico-formal de unos postulados jurídicos, como es el caso de la simbolización que hace FERRAJOLI de ciertas máximas jurídico-penales, tiene un grave inconveniente práctico, a saber: intimida al lector no familiarizado con ese lenguaje, quien muchas veces ni siquiera está en condiciones, verdaderamente, de saber si la formulación lógica empleada es o no pertinente. En esta medida, ese expediente artificial sirve más para impedir que para propiciar la divulgación y discusión crítica de las ideas mismas que estén sobre el tapete. Es una herramienta del dogma. De allí que, y aunque esa no sea la intención expresa del autor, su recurso a la lógica formal se constituye, aunque sea por una vía indirecta, en una estrategia de inmunización (ALBERT) frente a potenciales críticas a su teoría.

Repito: no es que por principio la lógica formal, rectius: la formalización o simbolización lógica de unos principios jurídicos, deba estar vedada del campo jurídico, de antemano. Esta sería una afirmación absurda o, en todo caso, su validez dependería de qué se entienda por «lógica formal». Sin embargo, la cuestión principal es la pragmática del discurso judicial, o sea, unas prácticas sociales concretas sobre las cuales esa formalización pueda o no tener unos efectos. ¿Los tiene, o es probable que llegue a tener, realmente? A este respecto, ha dicho también HABA:

Recurrir a un lenguaje [lógico] artificial en el derecho serviría para otorgarle mucha más precisión al razonamiento jurídico, y cabría entonces la posibilidad de someterlo a unos verdaderos controles de racionalidad... Ahora bien, es indudable que los lenguajes formalizados se benefician, si nos limitamos a ellos en sí mismos, de un alto grado de intersubjetividad, muy por encima del que alcanzan los lenguajes naturales. Pero nuestro asunto es saber en qué medida son aplicables lenguajes de aquella índole para solucionar cuestio-

20 E. P. HABA, «Razones para no creer en la actual Teoría (ilusionista) de la Argumentación», Doxa, 33, 2010, 321 y ss.; cita de la 324, nota 3. Señala, además, dicho autor: «Por lo demás, ¿̇al fin de cuentas qué son esos "axiomas" de FERRAJOLI sino argumentos de la tópica jurídica? Sólo que este autor los presenta de modo tal que fingen tener una precisión (univocidad) de que sus usos reales — ¡heterogeneidad/opcionalidad en las interpretaciones! - carecen en la práctica. Pero responder a tales preguntas requiere, por supuesto, desarrollos que aquí apenas he podido insinuar. Todo ello no quita, claro está, que el enciclopédico despliegue de iusescolástica reunido por FERRAJOLI bajo el Verbo Principia juris es, después de todo, todavía muchísimo más celestial (no sólo por sus axiomatizaciones, nivel máximamente disimulador) que en general las principales observaciones presentadas por las teorías "estándar". Lo de FERRAJOLI puede resultar hasta muchísimo más engañador todavía que otros ilusionismos — "argumentativistas" o no- pergeñados en la Teoría del Derecho: por ejemplo, todavía más que unas tesis como las vicentianamente más reputadas entre los simplismos de DwORKIN; justamente porque a aquel le sobra la ilustración, y también la pseudociencia, en que los simplismos difundidos por este último hacen agua míreseles por donde se les mire. En última instancia, solo al gusto de cada quien queda librado hasta qué punto se estime como de señalada "importancia", o antes bien como asunto de unas pedanterías escolástico-profesorales, tales o cuales diferencias entre esos autores, y muchas otras entre las tantas que abundan en Teoría del Derecho» («Callar o no callar... That is the question!», Doxa, 33, 369 y ss.; cita de la 383, nota 38). 
nes jurídicas. Y desde este ángulo, todo parece indicar que ellos ofrecen importancia muy secundaria, cuando no son hasta inconvenientes ${ }^{21}$.

\subsection{Tratar como definiciones «reales» (esencialistas) a unas que de hecho son definiciones estipulativas (contingentes)}

Definición estipulativa es aquella que reporta, por una voluntad de su autor, cierto significado específico para determinado objeto; o sea, aquella que se adopta por razones de conveniencia, utilidad o para enfatizar algún aspecto en especial del objeto definido ${ }^{22}$. No importa si la palabra que se define tiene, en otros contextos o en el lenguaje ordinario, significado bien distinto, pues a partir de ahora se le asigna otro significado por parte del autor. En esta medida, la definición estipulativa es «arbitraria»; mas esto no significa que una vez adoptado su significado no pueda, en el marco donde ha surgido, utilizarse correcta o incorrectamente. Con la definición se «estipula» o acuerda (de allí el nombre de esta definición) el alcance de la palabra para señalar el universo de objetos que se quiere comprender bajo ella; como así también, por eso mismo (en virtud de tal señalamiento justamente), cuáles se entiende excluir de dicho ámbito de significación. En este proceso se crea un nuevo uso del término, un significado (otro) que es conveniente u oportuno, o en todo caso se considera así, para los propósitos que desea alcanzar su autor, pues así es cómo, en cambio, se logra mantener suspendidos otros significados usuales o hasta dejarlos al margen. Por todo esto, se ha dicho que las definiciones estipulativas son libres (PASCAL, Les définitions sont très-libres).

Es importante indicar que las definiciones estipulativas carecen de lo que técnicamente se ha llamado en lógica: un «valor de verdad». Ninguna definición es verdadera o falsa en sí misma. Menos que menos, las estipulativas. El hecho de que estas últimas son construidas en forma expresa, por cierto autor bien determinado, precisamente para servirle a este (y a quienes le sigan) como instrumento mental dirigido al cumplimiento de alguna meta intelectual específica, y eventualmente también para obtener unas realizaciones prácticas condicionadas — real o supuestamente- por ese instrumento, no puede operar el milagro de hacer que tales convencionalismos verbales ( $\mathrm{ni}$ ningún otro) sean verdaderos por sí mismos. Con respecto a cualquiera de estos se trata, finalmente, de una invitación, una exhortación, y en algunos casos de un mandato, para que cierto auditorio (los lectores de ese texto y a quienes algunos de estos les transmitan esas mismas instrucciones) entienda una palabra en el sentido específico que ese autor le quiere asignar. Otra cosa es que también otras personas (auditorio) accedan a compartir este querer específico, lo cual puede acontecer - ya sean ellas unas pocas o acaso muchas- o no acontecer.

La definición estipulativa se diferencia de otros tipos de definición; por ejemplo, de la definición lexicográfica y de la definición real. La definición lexicográfica es aque-

${ }^{21}$ E. P. HABA, El espejismo de la interpretación literal. Encrucijadas del lenguaje jurídico, t. II, San José, Vlamarán, 2003, 158.

${ }_{22}$ Respecto a todo este apartado sobre definiciones recomiendo la lectura del excelente libro de R. RoBINSON, Definition, Oxford, Oxford University Press, 1972, de donde he tomado buena parte de lo aquí expuesto. 
lla donde se reporta el uso efectivo que se le da a una palabra en determinado contexto (por ejemplo, las definiciones del diccionario) ${ }^{23}$. La definición real es aquella que -al menos eso afirman quienes defienden su existencia - nos presenta la «esencia» de la cosa definida, lo que la hace característica, su «naturaleza».

Un ejemplo práctico, trivial, puede aclarar un poco lo dicho con respecto a estos distintos tipos de definición. Una persona puede definir un lápiz como «una barrita de grafito cubierta de madera que sirve para escribir o dibujar». Esto sería una definición lexicográfica, que coincide con la manera en que un diccionario corriente define lápiz. Igualmente, podemos decir: «Vamos a entender por lápiz un objeto en forma de cilindro que constituye a su vez un polígono regular». Una definición de este tipo podría adoptarse, por ejemplo, por parte de un matemático, para ilustrar lo que es un polígono; y así no hacer referencia alguna al grafito, que pasa a un segundo plano, a pesar de que en la definición lexicográfica de lápiz, utilizada en la vida cotidiana, el grafito es lo principal. Alguien interesado en brindar una definición «real» se preocuparía, por su parte, en encontrar aquello que hace que un lápiz sea un lápiz y no un bolígrafo, ni un marcador o una pluma; es decir, entonces se trataría de destacar su naturaleza «intrínseca», su «esencia» (asumiendo que tales cosas existan).

La definición real o esencial — a diferencia de la lexicográfica y la estipulativa— ha sido objeto históricamente de muchas disputas. Hay algunos autores (a los cuales me sumo) que sostienen que no existen tales definiciones reales (al menos como nos suelen ser explicadas), sino que ellas en verdad se asientan en una serie de confusiones. La principal de esas confusiones es pensar que detrás de una palabra ha de existir siempre una cosa, y peor aún, una «esencia» que hace que el uso de esa palabra respetando exactamente esta acepción específica, su significado «esencial», sea obligatorio en todos los contextos. Por esto, las definiciones reales están emparentadas con lo que se ha llamado en filosofía del lenguaje «naturalismo lingüístico», es decir: básicamente, la tendencia de atribuirle a todos los nombres un referente empírico bien determinado, o sea, pre-presuponer que entre la palabra y la cosa hay una identidad por fuerza ${ }^{24}$. Allí donde está la palabra o el nombre, allí mismo estaría — así se da por descontado— la «cosa» correspondiente: inecesariamente correspondiente, la única capaz de corresponderle de veras! Eso sí, a este respecto importa sobremanera no pasar por alto la fundamental comprobación señalada en el estudio de OGDEN y RICHARDS:

La concepción primitiva [del lenguaje] consiste, indudablemente, en que el nombre indica, o describe, la cosa. De donde se seguiría de inmediato que por la presencia del nombre uno podría demostrar la existencia de la $\operatorname{cosa}^{25}$.

En la creencia de que existe una definición real es básica también la idea de que hay un único significado verdadero, el cual hay que buscar afanosamente, para todo concepto. En el campo jurídico, esta idea es de especial importancia, pues no con poca frecuencia allí se habla de la «única solución correcta» para un determinado asunto o de la «naturaleza jurídica» de un X o Y concepto. R. ROBINSON ha concretado una lista

${ }^{23}$ RoBinSON nos dice al respecto: «Lexical definition is that sort of word-thing definition in which we are explaining the actual way in which some actual word has been used by some actual persons», ibid., 35 .

${ }_{24}$ Vid., al respecto, mi libro: Yo me engaño, tú te engañas, él se... Un repertorio de sofismas corrientes en las ciencias sociales, Isolma, San José, Costa Rica, 2011, 60.

${ }^{25}$ Cit. en ibid., 64. 
de vicios característicos que se encuentran presentes en la doctrina de las definiciones reales. $\mathrm{Al}$ respecto ha dicho:

Concluyo, pues, que la noción de una definición real es una confusión de al menos doce cosas distintas:

1. Una búsqueda de un significado idéntico en todos los usos de una palabra ambigua.

2. Una búsqueda de esencias.

3. Una descripción de una mera forma, dándole a ésta un nombre.

4. Una definición de una palabra, mientras se piensa erróneamente que no se está hablando de palabras [sino de cosas].

5. La aprehensión de una tautología determinada por una definición nominal.

6. Una búsqueda de una única causa.

7. Una búsqueda de una suerte de «llave maestra» que será capaz de explicar una infinidad de hechos.

8. La adopción y recomendación de unos ideales.

9. La [i. e., proceder a efectuar una] abstracción, la cual resulta ser [i.e., ahí es tomada como] mera forma.

10. El análisis, el cual termina por afirmar que una forma es simplemente un complejo de otras formas.

11. Una síntesis, la cual termina por afirmar que una cierta forma es simplemente una parte de un complejo de otras formas.

12. La invención de unos conceptos propios ${ }^{26}$.

Ahora bien, la idea central que quiero expresar en este apartado es la siguiente: muchas veces las personas que escriben en los más distintos campos del saber humano, sobre los más variados temas, construyen definiciones estipulativas para unos propósitos personales muy específicos, pero nos las presentan, consciente o inconscientemente, como si fueran definiciones reales. Se da ahí un expediente mental que bien podría llamarse la estrategia del caballo de Troya, pues se nos presenta tal o cual objeto, pero disfrazado de otra cosa. Creo que este es un grave error metodológico. Si establezco una definición en la cual quiero seleccionar determinado aspecto de la realidad, debo tener la honestidad para decirle al lector que dicha definición obedece a un interés mío, no es a otra cosa. Debo ser suficientemente franco para reconocer que mi propuesta de definición no abarca la totalidad de supuestos, ni siquiera cierta o ciertas otras partes importantes, entre todos aquellos que conforman la realidad concernida; por ende, que esa definición no es «universal», «verdadera», «real», «esencial», ni cosa que se le parezca. Al ser una definición estipulativa es también, y por principio, definición contingente: con «contingente» quiero decir que esta no es absoluta o necesaria, ni en el plano empírico ni en lógica.

FERRAJOLI se vale de la estrategia siguiente: ofrece una serie muy detallada de definiciones, por demás con carácter de definiciones persuasivas (STEVENSON), las que evidentemente son una manera - y ni siquiera digo que esta sea forzosamente «ilegítima»-, de presentar ciertos ángulos del problema, pero implícitamente provoca la impresión de que esa definición nos advierte sobre la «esencia» de lo que se dice mediante el término en cuestión. Él tampoco pone algún empeño, ni poco ni mucho, en desvanecer esta impresión.

\footnotetext{
26 R. Robinson, op. cit., 189-190.
} 
Es cierto, podemos admitir como un hecho de la vida intelectual que cada autor goza de lo que un filósofo alemán llamaba la «libertad de definición» (Definitionsfreiheit $)^{27}$. Por tanto, él puede utilizar los conceptos como le venga en gana; claro está, con el riesgo de que nadie le entienda. El problema central, sin embargo, no reposa en que se utilicen o no unas definiciones estipulativas. Por ejemplo, se puede definir «garantismo» como un modelo normativo de estricta legalidad, como una teoría jurídica de la validez y de la efectividad o como una filosofía política ${ }^{28}$. El problema no consiste en aceptar o no esa definición propuesta por FERRAJOLI. El problema es más bien por qué debo aceptar yo, o cualquier otra persona, precisamente esa definición. Sobre todo, este es el punto medular de la cuestión, averiguar qué ventaja comparativa - $\mathrm{y}$ desde qué punto de vista - se obtendría de la susodicha propuesta de definición — ide esta, solamente de esta misma! - si la comparamos con cualesquiera otras definiciones posibles (sean estas unas ya existentes u otras que acaso se venga a proponer).

Dicho con palabras más gráficas: la fuerza, por llamarle así, en cuanto a validez científica de una definición no se sigue ni de la fama de su autor, ni de la cantidad de elementos que aquella comprenda, ni siquiera de si resulta o no idónea para los efectos que ese autor se proponga personalmente. La validez de ese orden depende única y exclusivamente de si dicha propuesta de definición es, en el plano teorético mismo, más adecuada que otras definiciones para explicar el problema al cual ella pretende ofrecer respuesta. Ahora bien, cómo pueda ser esto de «adecuada» (qué significa ahí, en especie, esta palabra) dependerá, obviamente, de cuáles sean respectivamente las consecuencias de adoptar una u otra definición. Es ahí precisamente, en el plano de las consecuencias prácticas, donde se mide la capacidad de rendimiento de una teoría científica y el de cualquier definición. Sobre esa capacidad de rendimiento (Leistungsmerkmale $)^{29}$ debe dar cuenta el propio autor que propone la definición o la teoría en cuestión. Sería no poco curioso sostener ( $i$ si es abiertamente!) que quien proponga una teoría no tiene por qué mostrar — y demostrar - las ventajas propias que él pretenda para esa teoría en comparación con las restantes; recordemos que generalmente, en el campo científico, una teoría, para ser aceptada, ha de superar en alguna medida las deficiencias o debilidades de las teorías adversas.

Tampoco en el caso específico de FERRAJOLI basta, pues, con que defina «garantismo penal»o «teoría garantista» de la manera en que lo ha hecho. Lo que él tiene que mostrarnos — esto es, a quienes no le obsequiamos la comodidad de constituirnos simplemente (como aquel profesor español) en unos «creyentes» a priori- es qué aspectos específicos de su teoría son más fuertes que otras teorías paralelas de la dogmática penal, en todo caso frente a las bastante conocidas entre ellas. Para intentar esa comparación, indispensable, se me ocurre que algunas de las inquietudes que pueden surgir, en un lector atento de los esquemas presentados por nuestro autor, son las siguientes:

- ¿De qué sirve, en el plano teorético y en el práctico, definir «garantismo» penal a partir de conceptos altamente indeterminados («libertad personal», «intervención

27 R. Zippelius, Rechtsphilosophie, 3. Auflage, Munich, C. H. Beck Verlag, 1994, 4 y ss.

${ }_{28}$ Para detalles en cuanto a estas definiciones, vid. el Apéndice ubicado al final del presente trabajo.

29 Para el tema de la capacidad y los criterios de rendimiento de una determinada ciencia o disciplina, vid. para el caso jurídico: Hans AlBert, La ciencia del derecho como ciencia real, trad. de M. E. SALAS, México, Fontamara, 2007. 
arbitraria», «necesidad», «daño», «sustancial», «material», «formal», «legitimidad») y sobre la base de definiciones persuasivas («garantismo penal», «modelo normativo», «estricta legalidad», «Estado de derecho», «democracia», «esfera de lo indecidible», «necesidades vitales de todos»)? ¿Qué ventajas se obtienen de este procedimiento, en el plano científico?

- ¿Es tal definición estipulativa, la presentada por ese autor, una construcción que sirva exclusivamente a propósitos que son nada más —o, en todo caso, muy primordialmente- de carácter académico-intelectual? ¿O será que aquella tiene también una pretensión práctica, propia del derecho como tecnología social (ALBERT, POPPER)?

- ¿Cómo podría alguien saber, con algún buen grado de intersubjetividad, que los elementos de juicio aportados por FERRAJOLI en su «teoría del garantismo» son mejores para esclarecer ciertos problemas penales reales en concreto? ¿Cuál es el criterio de rendimiento del cual parte su teoría?

- ¿Qué tipo de «teoría» es la de FERRAJOLI? ¿Es una teoría en sentido puramente dogmático-normativo o es una teoría empírica, o en parte lo uno y en parte lo otro? Y en este último caso, ¿cómo distinguir allí estos dos tipos de componentes entre sí?; más, ¿a qué requisitos de prueba (intersubjetivos) quedan respectivamente sujetos cada uno de ellos? Por lo demás, ¿dicho autor toma acaso allí el concepto «teoría» en algún sentido muy amplio, y cuál sería ese? O bien, chay en él una pretensión de validez mayor propia de la filosofía de la ciencia: por ejemplo, el de una teoría en el sentido del esquema de HEMPEL-OPPENHEIM ${ }^{30}$ o el del racionalismo crítico?

- ¿Mediante qué elementos es posible «testar» (verificar, falsar) la teoría del garantismo penal? ¿Cuáles son los criterios de validez, verdad o corrección que allí se manejan?

No estaría de más —me parece— que, si no el propio FerRAJOLI (¡demasiado pedir!), tal vez algunos de sus «creyentes» se aboquen a aclarar tales interrogantes. Claro que, si así lo hicieren, no se ve cómo podrían seguir siendo simplemente «creyentes».

\subsection{Apelar a unos principios generales que operan como parapetos lingüísticos}

Me sorprende cómo aun hoy día muchos juristas, en este caso FERRAJOLI, continúan valiéndose de la noción de principios generales del derecho como si ese concepto fuera claro y libre de todo tipo de problemas. Mi sorpresa obedece, básicamente, a que

30 Este esquema tiene la siguiente forma: SI (se presentan ciertas circunstancias), ENTONCES (se producen ciertos efectos). Ejemplo: SI una persona enfrenta graves problemas financieros y familiares, ENTONCES es probable que cometa ciertos delitos (por ejemplo hurtos). Esta primera parte del esquema (conocido como el «explanans») se debe complementar con dos partes adicionales, a saber: con las condiciones marginales y con el llamado «explanandum». El esquema completo de lo que es una teoría explicativa, en este sentido estricto de la teoría de las ciencias, sería, entonces, el siguiente:

Esquema de Explicación:

1. Teoría: SI una persona tiene graves problemas financieros y familiares, ENTONCES comete, con mayor frecuencia, ciertos delitos (por ejemplo hurtos).

2. Condiciones marginales: La persona $X$ tiene graves problemas financieros $y$ familiares.

3. Explanandum: La persona X cometió un delito de hurto. Al respecto, vid. mi trabajo «La explicación científica en las ciencias sociales: Consideraciones intempestivas contra el dualismo metodológico», en Revista Reflexiones, núm. 84 (2), San José, Costa Rica, Facultad de Ciencias Sociales de la Universidad de Costa Rica, 2005, 51-60. 
desde hace ya décadas en la filosofía y en la teoría básica del derecho ha quedado más que demostrado cómo bajo dichos principios jurídicos cabe, prácticamente, cualquier cosa. No es raro así que, ya desde hace bastante tiempo atrás, CARRIó supo distinguir nada menos que siete focos distintos de significación en la expresión «principio del derecho»:

Podemos decir que ese concepto [el de principio] está emparentado:

1. Con las ideas de «parte o ingrediente importante de algo», «propiedad fundamental», «núcleo básico», «característica central».

2. Con las ideas de «regla, guía, orientación o indicación generales».

3. Con las ideas de «fuente generadora», «causa» u «origen».

4. Con las ideas de «finalidad», «objetivo», «propósito» o «meta».

5. Con las ideas de «premisa», «inalterable punto de partida para el razonamiento», «axioma», «verdad teórica postulada como evidente», «esencia», «propiedad definitoria».

6. Con las ideas de «regla práctica de contenido evidente»; «verdad ética incuestionable».

7. Con las ideas de «máxima», «aforismo», «proverbio», «pieza de sabiduría práctica que nos viene del pasado y que trae consigo el valor de la experiencia acumulada y el prestigio de la tradición» ${ }^{31}$.

Sin embargo, FERRAJOLI piensa, en contra de toda esta tradición crítica y de todas las abrumadoras evidencias teoréticas presentadas al respecto en múltiples estudios desde hace muchos años, que el sistema garantista del derecho penal está construido justamente sobre la base de diez principios generales de este tipo. Al respecto dice:

«Estos diez principios, ordenados y conectados aquí sistemáticamente, definen —con cierto forzamiento lingüístico - el modelo garantista de derecho o de responsabilidad penal, esto es, las reglas del juego fundamentales del derecho penal». Según él, esos principios: «...han sido ulteriormente incorporados, más o menos íntegra y rigurosamente, a las constituciones y codificaciones de ordenamientos desarrollados, convirtiéndose así en principios jurídicos del moderno estado de derecho» ${ }^{32}$. Los diez principios en cuestión son:
A1 Nulla poena sine crimine.
A2 Nullum crimen sine lege.
A3 Nulla lex (poenalis) sine necesitate.
A4 Nulla necessitas sine iniuria.
A5 Nulla iniuria sine accione.
A6 Nulla actio sine culpa.
A7 Nulla culpa sine indicio.
A8 Nullum iudicium sine accusatione.
A9 Nulla accusatio sine probatione.
A10 Nulla probatio sine defensione ${ }^{33}$.

Lo que no nos advierte FERRAJOLI, aunque ya desde hace muchos años lo había visto J. ESSER ${ }^{34}$, es que dichos principios — aunque se venga a escribirlos en latín, se les dé una notación lógica, se les considere como formando un «sistema garantista» o se

31 G. R. CARRIó, Notas sobre derecho y lenguaje, 209-210. Para un examen muy pormenorizado de la vasta plurivocidad y plurifuncionalidad de ese comodín del lenguaje jurídico, puede verse también: E. P. HABA y J. F. BARTH, Los principios generales del derecho, San José, Editorial Investigaciones Jurídicas, 2004.

32 L. FERRAJOLI, Derecho y razón, 93.

33 Id.

34 J. Esser, Grundsatz und Norm in der richterlichen Fortbildung des Privatrechts, 4. Aufl., Mohr, Tübingen, 1990. 
les conecte mediante toda suerte de «implicaciones»— son, en realidad, arcilla en las manos de los legisladores substitutos (RüTHERS); o sea, de los operadores del derecho, en especial de los jueces. Tales comodines sirven como «puertas abiertas» para que ingresen los ideales, los valores y hasta los prejuicios de los jueces, a la hora de dictar una sentencia. Estos principios no resuelven casos concretos. Los casos los resuelven las personas. Y las personas entienden cosas muy distintas bajo palabras como «necesidad», «daño», «culpa». De allí que «muchísimas cosas, que no lo ameritan, llevan el nombre de principio del derecho» (K. F. RÖHL) ${ }^{35}$

\section{Excurso: ¿Qué resulta del garantismo penal al verterlo como sopa de letras?}

De verdad - y me disculpo con el lector por dejar desbordar un poco mis emociones más de lo que los eufemismos académicos amparan - hay que armarse de una paciencia formidable, como también de una flojedad de inferencias no menos considerable, para no desesperar cuando FERRAJOLI sostiene que todos esos diez principios se encuentran «implicados» lógicamente, y que así es cómo de ellos se derivarían, «por la transitividad de la implicación», otros muchos teoremas o principios. De tal suerte que su «sistema garantista completo» luciría, según él, nada más y nada menos que de la siguiente manera (Derecho y razón, 110 y ss.):

Si indicamos con las letras «PE», «DE», «LE», «NE», «IN», «AT», «CU», «U «AC», «PR»y «DF» los términos «pena» (poena), «delito» (crimen), «ley (penal)» (lex), «necesidad» (necessitas), «ofensa» (iniuria), «acción» (actio), «culpabilidad» (culpa), «juicio» (iudicium), «acusación» (accusatio), «prueba» (probatio) y «defensa» (defensio), y con los símbolos «—que son los signos, respectivamente, de la negación, la conjunción, la disyunción y la implicación-, los diez axiomas de nuestro mini-sistema SG pueden expresarse con las siguientes fórmulas:

$$
\begin{aligned}
& \text { A1 } \neg(\text { PE. } \neg \text { DE) } \\
& \text { A2 } \neg \text { (DE. } \neg \text { LE) } \\
& \text { A3 } \neg \text { (LE. } \neg \text { NE) } \\
& \text { A4 } \neg(\text { NE. } \neg \mathrm{IN}) \\
& \text { A5 } \neg \text { (IN. } \neg \text { AT) } \\
& \text { A6 } \neg(\text { AT. } \neg \mathrm{CU}) \\
& \text { A7 } \neg(\text { CU. } \neg \text { JU) } \\
& \text { A8 } \neg(\text { JU. } \neg \text { AC) } \\
& \text { A9 } \neg(\text { AC. } \neg \text { PR) } \\
& \text { A10 } \neg(\text { PR. } \neg \text { DF) }
\end{aligned}
$$

Las cuales equivalen, respectivamente, a las siguientes implicaciones:

$$
\begin{aligned}
& \text { T1 (PE } \rightarrow \text { DE) } \\
& \text { T2 (DE } \rightarrow \text { LE) } \\
& \text { T3 (LE } \rightarrow \text { NE) } \\
& \text { T4 (NE } \rightarrow \text { IN) } \\
& \text { T5 (IN } \rightarrow \text { AT) } \\
& \text { T6 (AT } \rightarrow \text { CU) } \\
& \text { T7 (CU } \rightarrow \text { JU) } \\
& \text { T8 (JU } \rightarrow \text { AC) } \\
& \text { T9 (AC } \rightarrow \text { PR) } \\
& \text { T10 (PR } \rightarrow \text { DF) }
\end{aligned}
$$

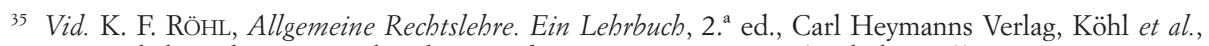
2001, en especial el excelente apartado sobre «Rechtsprinzipien», 251 y ss. (trad. de MES). 
De donde derivan, por la transitividad de la implicación, los siguientes cuarenta y cinco teoremas:

\begin{tabular}{|l|l|}
\hline $\mathrm{T} 11(\mathrm{PE} \rightarrow \mathrm{LE})$ & $\mathrm{T} 12(\mathrm{PE} \rightarrow \mathrm{NE})$ \\
\hline $\mathrm{T} 13(\mathrm{PE} \rightarrow \mathrm{IN})$ & $\mathrm{T} 14(\mathrm{PE} \rightarrow \mathrm{AT})$ \\
\hline $\mathrm{T} 15(\mathrm{PE} \rightarrow \mathrm{CU})$ & $\mathrm{T} 16(\mathrm{PE} \rightarrow \mathrm{JU})$ \\
\hline $\mathrm{T} 17(\mathrm{PE} \rightarrow \mathrm{AC})$ & $\mathrm{T} 18(\mathrm{PE} \rightarrow \mathrm{PR})$ \\
\hline $\mathrm{T} 19(\mathrm{PE} \rightarrow \mathrm{DF})$ & $\mathrm{T} 20(\mathrm{DE} \rightarrow \mathrm{NE})$ \\
\hline $\mathrm{T} 21(\mathrm{DE} \rightarrow \mathrm{IN})$ & $\mathrm{T} 22(\mathrm{DE} \rightarrow \mathrm{AT})$ \\
\hline $\mathrm{T} 23(\mathrm{DE} \rightarrow \mathrm{CU})$ & $\mathrm{T} 24(\mathrm{DE} \rightarrow \mathrm{JU})$ \\
\hline $\mathrm{T} 25(\mathrm{DE} \rightarrow \mathrm{AC})$ & $\mathrm{T} 26(\mathrm{DE} \rightarrow \mathrm{PR})$ \\
\hline $\mathrm{T} 27(\mathrm{DE} \rightarrow \mathrm{DF})$ & $\mathrm{T} 28(\mathrm{LE} \rightarrow \mathrm{IN})$ \\
\hline $\mathrm{T} 29(\mathrm{LE} \rightarrow \mathrm{AT})$ & $\mathrm{T} 30(\mathrm{LE} \rightarrow \mathrm{CU})$ \\
\hline $\mathrm{T} 31(\mathrm{LE} \rightarrow \mathrm{JU})$ & $\mathrm{T} 32(\mathrm{LE} \rightarrow \mathrm{AC})$ \\
\hline $\mathrm{T} 33(\mathrm{LE} \rightarrow \mathrm{PR})$ & $\mathrm{T} 34(\mathrm{LE} \rightarrow \mathrm{DF})$ \\
\hline $\mathrm{T} 35(\mathrm{NE} \rightarrow \mathrm{AT})$ & $\mathrm{T} 36(\mathrm{NE} \rightarrow \mathrm{CO})$ \\
\hline $\mathrm{T} 37(\mathrm{NE} \rightarrow \mathrm{JU})$ & $\mathrm{T} 38(\mathrm{NE} \rightarrow \mathrm{AC})$ \\
\hline $\mathrm{T} 39(\mathrm{NE} \rightarrow \mathrm{PR})$ & $\mathrm{T} 40(\mathrm{NE} \rightarrow \mathrm{DF})$ \\
\hline $\mathrm{T} 41(\mathrm{IN} \rightarrow \mathrm{CU})$ & $\mathrm{T} 42(\mathrm{IN} \rightarrow \mathrm{JU})$ \\
\hline $\mathrm{T} 43(\mathrm{IN} \rightarrow \mathrm{AC})$ & $\mathrm{T} 44(\mathrm{IN} \rightarrow \mathrm{PR})$ \\
\hline $\mathrm{T} 45(\mathrm{IN} \rightarrow \mathrm{DF})$ & $\mathrm{T} 46(\mathrm{AT} \rightarrow \mathrm{JU})$ \\
\hline $\mathrm{T} 47(\mathrm{AT} \rightarrow \mathrm{AC})$ & $\mathrm{T} 48(\mathrm{AT} \rightarrow \mathrm{PR})$ \\
\hline $\mathrm{T} 49(\mathrm{AT} \rightarrow \mathrm{DF})$ & $\mathrm{T}$ ( $)(\mathrm{CU} \rightarrow \mathrm{AC})$ \\
\hline $\mathrm{T} 51(\mathrm{CU} \rightarrow \mathrm{PR})$ & $\mathrm{T} 52(\mathrm{CU} \rightarrow \mathrm{DF})$ \\
\hline $\mathrm{T} 53(\mathrm{JU} \rightarrow \mathrm{PR})$ & \\
\hline $\mathrm{T} 55(\mathrm{AC} \rightarrow \mathrm{DF})$ & \\
\hline
\end{tabular}

[...] Mediante la conjunción de los consecuentes de todos los teoremas que tienen el mismo antecedente se obtienen las diez tesis siguientes, que expresan sintéticamente el sistema SG completo:

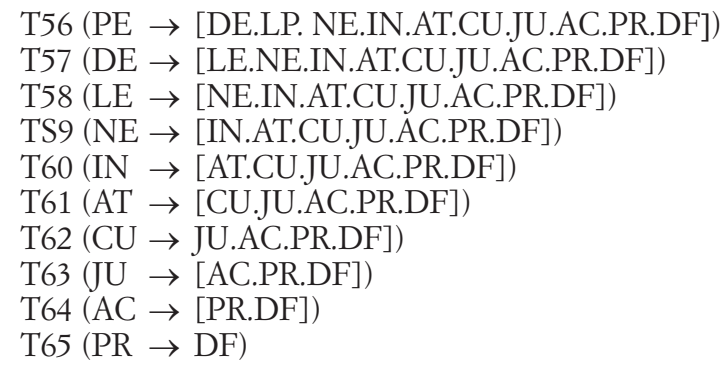

Y mediante la disyunción de los antecedentes de todos los teoremas que tienen el mismo consecuente se obtienen, en cambio, las diez tesis siguientes, que expresan también, aunque de manera distinta, el sistema SG completo: 


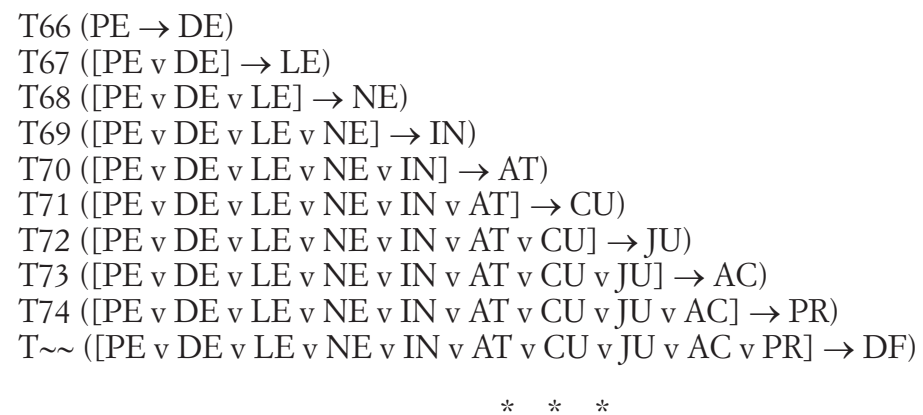

Ahora bien, lo que el lector ha de tener aquí presente es que toda esta simbolización es, básicamente, para poner en lenguaje complicado lo que ya de por sí se había dicho y se sabía en lenguaje ordinario. ¡Cero novedad por cuanto se trate de los contenidos conceptuales en sí mismos! Me atrevo a sugerir que no es cuestión de dejarse intimidar por la ostentación de jerigonza profesoral bajo la que aquí se cobija FERRAJOLI, sino atreverse a preguntar: ¿qué significa eso, semejante bombardeo de siglas y flechas, en el fondo? Una vez descorrida esa cortina, aparece a plena luz del día que se trata de cosas sencillas, bastante conocidas desde hace mucho tiempo en el medio jurídico, únicamente que dichas ahí de una forma que aparenten tener mucho rigor y cientificidad. Esto es: conseguir aparentarlo ante los ojos de gente a quienes les basta con, o hasta consideran indispensable, que cualquier idea les sea presentada mediante unos trazados de siglas — verdadera o aparentemente sujetas a alguna notación lógico formal (;cualquiera!) — o estar bien nutrida en cuadros numéricos (¡cualesquiera!), para entonces dar por descontado, sin más, en que ahí ha de anidar el saber máximamente confiable, lo «científico» por excelencia.

Considérese, por ejemplo, el axioma: T1 (PE $\rightarrow$ DE). Este significa, simplemente, que para aplicar una pena debe darse un delito. Otro axioma: T2 (DE $\rightarrow$ LE), para que se dé un delito debe existir una ley. Otros más: T3 (LE $\rightarrow$ NE), la ley solo ha de darse sobre la base de la necesidad y la necesidad sobre la base del daño T4 (NE $\rightarrow$ IN) y que este daño presupone una acción en sentido penal. Y así sucesivamente. Sin embargo, lo interesante, lo importante de veras no está en poner con letritas y símbolos lógicos todo eso, sino en saber qué entienden o vayan a entender los jueces, y los demás operadores jurídicos, por «necesidad», por «daño», por «culpabilidad»... ¡Difícil imaginar un ejercicio más vano de «siglas» $\mathrm{y}$ «flechas» (para sintetizarlo alguna manera)!

\subsection{Definir lo desconocido por medio de lo desconocido}

El propósito de acuñar una definición es, por lo general, precisar, organizar o delimitar el ámbito de explicación de unos fenómenos. De allí que definir es siempre seleccionar. Alguien escoge, sobre la base de determinados intereses, ya sean estos cognitivos o no, aquellos aspectos que él quiere resaltar, delimitándolos con respecto a otros que quedan fuera de la esfera de lo definido. Definir es también, por consiguiente, un acto de poder de quien define. Y la palabra «poder» se usa aquí en un sentido muy amplio. Hay que tener claro que cuanto más limitada sea la esfera de lo definido, más fuerza de determinación tendrá la definición ofrecida. Una definición que incluye demasiados entes resulta, por ello, débil desde el punto de vista científico. De allí que exista una relación inversa entre fuerza explicativa y amplitud de la definición. Así, por ejemplo, si yo defino el ser humano como un organismo bípedo, en realidad no he logrado mayor cosa; pues la cantidad de seres bípedos es muy extensa, de tal manera 
que uno podría terminar, como en la conocida anécdota de PLATÓN, definiendo «ser humano» como una gallina sin plumas.

Pienso que FERRAJOLI hace mucho eso. Él nos define algunos conceptos muy vagos y generales valiéndose de otros conceptos todavía más vagos más y generales que los primeros. A fin de cuentas, con ello se logra poco o nada: ;trocar desconocido por desconocido! Recordemos, nada más y como mera ilustración, la definición absolutamente general que dicho autor ofrece del garantismo penal: [T]écnicas de defensa de los derechos de libertad y, entre ellos, en primer lugar, el de la libertad personal, frente a las intervenciones arbitrarias de tipo policial o judicial... Cabe preguntarse: ¿Cuáles técnicas en concreto? ¿Qué tipo de técnicas? ¿De cuáles derechos de libertad se trata? ¿Cómo se entenderá ahí el concepto «libertad personal»? ¿Cuáles son las intervenciones «arbitrarias», a qué criterios en concreto se ha de recurrir para distinguir sin mayores dudas entre estas mismas y las que se considere legítimas? La estrategia argumentativa que generalmente utiliza FERRAJOLI consiste, después de todo, esencialmente en acumular detalles sobre detalles; si bien cada uno de estos resulta ser, a fin de cuentas, no menos indeterminado que los precedentes, por su general orfandad de criterios para localizar de manera intersubjetivamente acreditada cuáles serían sus eventuales objetos de referencia específicos en la práctica. Lo que él hace no es otra cosa que ir agregando a la definición del concepto primitivo una lista muy amplia de atributos muy generales, los cuales en definitiva no aportan nada de fondo para conseguir limitar de veras las definiciones así propuestas. Esta «técnica» produce un doble efecto:

i) Una apariencia de rigor y precisión. Se cree que cuanto más atributos se le asignen a un sustantivo, más precisa será la definición. Esto es falso. La precisión se lograría si los atributos que se le añaden al concepto primigenio fuesen acaso, ellos mismos, más concretos en su alcance para delimitar los eventuales objetos de referencia que tal concepto general. Dicho de manera puntual: nadie puede alcanzar precisión por medio de unas fórmulas lingüísticas vacías o de conceptos bastante indeterminados o de definiciones persuasivas, como eso de que se encuentra conformado en general el repertorio de definiciones ofrecidas por FERRAJOLI a lo largo de su libro.

ii) Una apariencia de suministrar un conocimiento profundo sobre la materia tratada. Hay que tener presente que no toda precisión analítica es pertinente o genera conocimiento aprovechable científicamente. La precisión es buena, indudablemente, salvo cuando se trata de una falsa precisión (VAZ FERREIRA) [recuérdese lo expuesto más arriba, en el punto (2)]. No se adquiere algún conocimiento que tenga envergadura mayor acerca de un fenómeno o grupo de fenómenos a fuerza de dividir en muchísimas categorías cierto concepto que de alguna manera los comprende. Partir pelos indefinidamente no es el arte principal de la peluquería. El análisis, entendiendo por análisis la división, puede más bien convertirse en una cortina de humo para «no tomar el toro por los cuernos», rehuir las incomodidades de enfrentar de manera directa el problema examinado ahí (supuestamente). Se trata, en definitiva, de unos expedientes discursivos para escaparse por la tangente del compromiso de verse en situación de tener que ofrecer, al contrario, alguna solución concreta para problemas prácticos «vivientes» del derecho penal.

No tengo más remedio, me parece, que traer aquí a colación un ejemplo «dramático» (diría yo) tomado del propio FERRAJOLI, alguno entre tantísimos posibles de los con- 
tenidos en su obra, para ilustrar mi punto de vista. Pero, al poner este ejemplo, necesito pedirle paciencia y mucha tenacidad al lector, para alcanzar a no perderse en la lectura de lo que ahí se dice; solamente así, mediante una muy firme disposición suya a hacer tal esfuerzo, aun con todo lo intrincado del camino (elegido por el propio FERRAJOLI), ha de resultar patente mi tesis al respecto, eso que entiendo poder hacer ver mediante dicho ejemplo. Veamos, entonces, el procedimiento utilizado por nuestro autor para darle contenido (según él), o sea, definir, lo que es un «Estado de derecho», concepto que es de lo más vago e indeterminado (de hecho, cualquier dictadura siempre afirma que se vive en un «Estado de derecho»). He aquí la cascada descendente de definiciones - me limitaré a destacar cinco grupos de ellas- que él propone para supuestamente delimitar bien ese concepto (trato de presentarla de manera bastante gráfica):

I. Señala FerRAjoli que el Estado de derecho es aquel donde existe:

i) o un gobierno sub lege, vale decir, sometido a las leyes;

ii) o aquel donde hay un gobierno per leges, vale decir, dominado mediante leyes generales y abstractas.

II. El poder sub lege posee, a su vez:

iii) un sentido débil, lato o formal: el poder es conferido por ley y ejercido en la forma allí establecida y,

iv) un sentido fuerte, estricto o sustancial, vale decir, que el poder debe ser limitado por la ley.

III. Estas dos nociones del Estado de derecho se deben asociar, a su vez, con dos conceptos claves para FERRAJOLI:

v) el concepto de validez formal, el cual exige únicamente una definición de las formas en que se ejerce el poder y los sujetos titulares de ese poder;

vi) y el concepto de validez material, el cual exige adicionalmente que estén claramente definidas las materias de competencia y los criterios de decisión.

IV. Siendo esto así, aquí «Estado de derecho» es sinónimo de «garantismo», lo cual a su vez da pie a distinguir entre:

vii) una legitimación formal, por un lado, y

viii) una legitimación material o sustancial, por el otro;

en otros términos, entre:

ix) una legalidad en sentido amplio y

x) una legalidad en sentido estricto.

V. Todos esos conceptos se materializan, a su vez, en dos formas distintas de Estado:

xi) el Estado de derecho liberal,

xii) el cual a su vez cuenta con unas garantías liberales negativas,

xiii) y el Estado de derecho social,

xiv) este último con sus garantías sociales positivas.

VI. Además:

$\mathrm{xv})$ 
Lo reproducido es una versión algo abreviada de la definición de FerRAJOLI. Él hace todavía más divisiones y subdivisiones, clasificaciones y subclasificaciones. Es más, yo creo (pero eso habría que demostrarlo) que es posible convertir TODO el libro de FERRAJOLI a un esquema similar al dibujado arriba. De hecho, algunas de sus notaciones lógicas apuntan justamente a eso: lo que hasta ahí él había dicho en lenguaje ordinario, a continuación traspasarlo en una simbología lógica del estilo indicado. Ahora quiero que el lector preste especial atención a dónde nos conduce la definición de FerRAJOli de «Estado de Derecho» y, especialmente, cuáles son los atributos específicos mediante los que él intenta circunscribir y darle contenido distintivo a esas definiciones. Si se examina a fondo cada uno de esos atributos (subrayados por mí al destacarlos en cursivas), no es difícil advertir, en cuanto nos preguntamos cuáles serían necesariamente sus contenidos concretos, que se trata, dicho sin reservas, de un buen «recetario» de fórmulas vacías («formal», «material», «positivo», «negativo», «social», «liberal»). Antes que aclarar la percepción de cómo sean las situaciones en los hechos y ofrecer unas pistas aprovechables para poder acomodarlas de mejor manera en la práctica, esa densa neblina de clasificaciones termina por embrollar al máximo toda eventual conciencia lúcida acerca de las posibilidades normativas reales en un medio social dado. Semejantes clasificaciones no constituyen un medio para poder discernir con nitidez alternativas de regulación jurídica prácticas, sino que son principalmente, de hecho, expedientes discursivos que desvían la atención hacia otras cosas: hacia unas elucidaciones de palabras y entre palabras — musica di parole - entonadas como unos conjuros de magia verbal.

Por lo demás, bien cabría preguntarle al propio autor de estos enjambres de clasificaciones: ¿por qué detenerse precisamente allí mismo, en los puntos finales adonde se le ha ocurrido venir a desembocar por su cuenta? ¿Por qué no seguir «precisando» aun más los conceptos empleados? ¿Por qué no ofrecer todavía algunos cuantos atributos adicionales, differentia specifica, a la noción general? Estoy seguro que una persona con suficiente imaginación, el mismo FERRAJOLI sin duda, puede encontrar muchas otras divisiones y subdivisiones que agregar al esquema general. Siempre es posible pergeñar, para cualquier concepto del lenguaje, algún nuevo matiz o un nuevo uso que pueda atribuírsele. Vale la pena recordar la insuperable descripción que al respecto hacían OGDEN y RiCHARDS, y que viene como anillo al dedo para describir el procedimiento empleado por FERRAJOLI:

Supongamos que alguien afirme: el gosta distima a los doches. Nadie sabe lo que esto significa; yo tampoco. Pero si suponemos que eso es castellano, sabemos que los doches son distimados por el gosta. Sabemos además que un distimador de doches es un gosta. Además, si los doches son galones, sabemos que algunos galones son distimados por el gosta. Y así podemos seguir, $y$, en efecto, a menudo seguimos ${ }^{36}$.

Las preguntas cruciales son, empero, las siguientes: ¿Hemos avanzado en el conocimiento de la materia jurídico penal a raíz de esa definición de FERRAJOLI? ¿Qué conocimiento tenemos ahora de la cuestión que no lo tuviéramos antes? ¿Qué nuevo ángulo se nos ha abierto ante nuestro horizonte de percepción? ¿Cuáles son los criterios concretos para distinguir entre los elementos formales y los sustanciales del Estado

36 C. K. OGden e I. A. Richards, El significado del significado. Una investigación sobre la influencia del lenguaje en el pensamiento y sobre ciencia simbólica, trad. de E. PRIETO, 2. ${ }^{a}$ ed., Buenos Aires, Paidós, $1964,63$. 
de Derecho? ¿Puede ofrecernos FerRajoli ejemplos puntuales de dichos elementos? Me disculpo por la franqueza, pero siento que no solamente no tenemos ningún conocimiento adicional, sino que incluso estamos peor que al inicio. Y digo peor, pues ahora la cuestión se ha vuelto más confusa. El único conocimiento que con ello hemos adquirido (y no es nada nuevo) es saber que un pelo se puede dividir mentalmente en toda la cantidad de partes que uno quiera (Haarspaltemaschine...), si se tiene el gusto y la paciencia como para venir a entretenerse en lides de esa naturaleza.

\subsection{Pasar por alto la distinción entre semántica y pragmática}

Es muy conocida, incluso por el propio FerRAJOLI, la diferencia que señaló Ch. MORRIS entre el nivel semántico de una teoría y su nivel pragmático. En tal sentido, nivel semántico es el plano puramente lingüístico, cómo se concibe las interrelaciones entre los conceptos y los objetos (reales o ideales, concretos o abstractos) que designa o denota la formulación considerada. Por su parte, el nivel pragmático de esta misma expresión se refiere a las maneras diversas en que los conceptos así expresados se emplean, de hecho, en determinadas prácticas sociales. Igualmente, voy a asumir como premisa, aunque es obvio que el lector puede aceptar o no esta premisa, que en el derecho penal, como conjunto de proposiciones jurídicas y como práctica social del castigo relacionada con ellas, resultan muy importantes los dos niveles: el semántico y el pragmático. Me parece que el propio FERRAJOLI estaría de acuerdo con estas puntualizaciones básicas.

Ahora bien, yo pienso que la teoría garantista de FERRAJOLI constituye, a pesar de lo que él pueda decir en contra, una doctrina de los conceptos; o para ser más radical aún, valiéndome de la feliz expresión de HABA, la teoría garantista es, en realidad, una novela de conceptos $^{37}$. Con esto no pretendo decir, por supuesto, que esos conceptos, y sus variopintas clasificaciones, no se refieran a nada jurídicamente hablando; sino simplemente que, de la manera cómo aquellos se utilizan por parte de FERRAJOLI y sus seguidores, lo que importa en su uso son unas posibles relaciones y sub-relaciones lógico-semánticas con otros conceptos, independientemente de cuanto suceda en la realidad —ipragmática lingüística! - del derecho penal aplicado. El libro de FERRAJOLI se me parece, permítaseme la metáfora, a una enorme telaraña tejida con finos hilos cuyo propósito no es cazar nada (¡ni una mosca, de las que vuelan!), sino mostrar la habilidad de la araña en su actividad tejedora. ¡Y la aracnea ferrajoliensis lo hace incansablemente, por más moscas que sigan volando libres al rededor!

Una de las acepciones del garantismo (la segunda, para ser exactos) que FERRAJOLI presenta, en el capítulo 13 de la obra citada, reza: una «teoría de la divergencia». Según este punto de vista, una función importante del garantismo sería denunciar el abismo que puede llegar a existir entre derecho válido y derecho efectivo. Dejemos al propio autor definir esa tesis:

Una aproximación semejante no es puramente «normativista» y tampoco puramente «realista»: la teoría que contribuye a fundar es una teoría de la divergencia entre normatividad y realidad, entre derecho válido y derecho efectivo, uno y otro vigentes. La desarrollada

37 Supra, nota al pie 9. 
en este libro es, por ejemplo, una teoría garantista del derecho penal normativista y realista al mismo tiempo: referida al funcionamiento efectivo del ordenamiento tal y como se expresa en sus niveles más bajos, sirve para revelar sus rasgos de validez y sobre todo de invalidez; referida a los modelos normativos tal y como se expresan en sus niveles más altos, es idónea para revelar su grado de efectividad y, sobre todo, de inefectividad. Bajo ambos aspectos el garantismo opera como doctrina jurídica de legitimación y sobre todo de deslegitimación interna del derecho penal... ${ }^{38}$.

Quisiera hacer notar un aspecto muy peculiar que se evidencia en este planteamiento de FERRAJOLI. Ciertamente, él enfoca el garantismo como una teoría que estaría, al menos en parte, referida a la realidad. En esta medida, si ello fuera cierto, cabría decir que hasta se le podría calificar, al menos en alguna medida, como un realista. No obstante, él traiciona precisamente ese postulado realista cuando desarrolla su propia teoría, esa que denomina «garantista». FERRAJOLI es realista hacia afuera, pero no hacia adentro, valga esa metáfora espacial. Es realista en cuanto llega a distinguir, al señalarlo literariamente como una observación de orden meramente general, entre el normativismo (lo que se dice en el papel con respecto a la ley) y lo que se hace en los tribunales (con esas mismas leyes). Pero, al parecer, es incapaz de aplicar ese mismo baremo fielmente a su propia teoría. Esto me recuerda un poco el «lema del fariseo»: hagan lo que yo digo, no lo que yo hago (un «fariseísmo», cabe aclarar, que en este caso está confinado a desempeños discursivos en unos planos de orden estrictamente teorético; desde luego, no entiendo referirme a ninguna otra clase de conductas del Sr. FERRAJOLI). Nuestro autor dice «realismo» ${ }^{39}$, pero en sus planteamientos hace «normativismo». Señalo esto, esencialmente por lo siguiente: si se adoptan al menos algunos de los postulados básicos del realismo (pensemos en ciertas tesis como las defendidas por FRANK, LlEWELLYN, Holmes, o recientemente por HABA), lo primero que habría que concluir es que casi la totalidad de lo dicho por FERRAJOLI sobre el garantismo, sobre sus principios y axiomas y sobre sus simbolizaciones lógicas, en lo fundamental constituye una pérdida de tiempo, eso reviste muy poca o casi ninguna utilidad para resolver los litigios efectivos que se presenten en tribunales penales reales.

Eso sí, no pretendo negar que tales o cuales de esas clasificaciones puedan tal vez llegar a ser invocadas en unas sentencias de tribunales. Sobre lo que advierto, es que la generalidad de ellas carecen, por la gran vaguedad de sus contenidos, de importancia efectiva para inclinar realmente la balanza de las resoluciones jurídicas concretas; o bien, ya no por vaguedad sino por trivialidad, tanto da que sean expresadas mediante unas acumulaciones de pedantismos como en FERRAJOLI o ponerlo de maneras tradicionales más sencillas. Como se sabe, a menudo en los discursos jurídicos se echa mano, entre otros referentes normativos, también a conceptos indeterminados. Entre estos, los hay que admiten poco menos que cualquier contenido normativo, hasta los más contradictorios entre sí, son lo que se llama propiamente «fórmulas vacías» (por ejemplo, «razonable»); mientras otros de ellos, aun siendo de contenido muy variable, no son tan enormemente ilimitados, en todo caso no admiten un rango tan desmesuradamente amplio de variantes (p. ej., «salario justo» para determinado tipo de trabajo estándar). Los respectivos letreros lingüísticos que remiten a tales conceptos funcionan, de hecho (su dimensión pragmática), como unas delegaciones para que su

\footnotetext{
38 L. FERRAJOLI, Derecho y razón, 852.

39 Id.., «...una teoría garantista del derecho penal normativista y realista al mismo tiempo...».
} 
intérprete autorizado - jueces, etc.- decida él mismo cuál, entre los varios sentidos posibles para la expresión invocada, será acogido en esa instancia. Por eso, a fin de cuentas resulta indiferente, en la práctica, si el juez invoca «a la letra» unas definiciones de la cantera de FERRAJOLI, para darle tinte «académico» a su fundamentación, o si simplemente acude a unos conceptos indeterminados en sus formas más tradicionales; bajo la condición, claro está, de que ya sea aquellos o estos pertenezcan al repertorio de lo retóricamente reconocido como «decible» en el medio jurídico. Después de todo, esos catálogos de pseudodefiniciones no son sino como unos letreros luminosos (valga la imagen), detrás de cuyas mamparas la trama verdadera de la obra así anunciada puede ser tanto que $A$ asesina a $B$ como que es $B$ quien asesina a $A$, o que ni siquiera haya ahí algún delito semejante, o que [...] [por ejemplo: en la Sala Constitucional de Costa Rica, no pocas veces unos fallos de gran efecto público se fundamentan diciendo que la medida en cuestión es o no es debidamente respetuosa de los principios constitucionales de «razonabilidad» y «proporcionalidad». Qué signifique específicamente, para el caso examinado, lo uno y lo otro, lo deciden sin más los propios magistrados según sus respectivas preferencias al respecto (no pocas veces es hasta mediante voto dividido: entonces lo que es «razonable» y «proporcional» para unos entre ellos, no lo es para los otros, y viceversa). No se ve cuál sería la diferencia en la práctica si, en cambio, se acudiere ahí a unas definiciones como las de FERRAJOLI, ya sea para aquellas mismas cuestiones o para unas donde en su resolución se invoque otros conceptos no menos manipulables].

Ahora bien, volvamos a lo de las susodichas actitudes intelectuales de orden «fariseico». La teorización de FERRAJOLI representa sólo un ejemplo más de eso en el seno de la Teoría del Derecho. De todas maneras, se trata de algo llamativamente peculiar: de tal manera se produce una singular dicotomía entre la comprensión racional y discursiva de unos postulados teoréticos, por un lado, y lo que son las aplicaciones jurídicas prácticas, por el otro. Así es como hay muchos juristas que conocen y hasta entienden cabalmente los argumentos específicos del realismo jurídico, pero quienes, cuando se trata de poner aquello en práctica y sacar las consecuencias de eso que han aceptado ellos mismos en la esfera teorética, en modo alguno lo hacen verdaderamente. En cambio, terminan aceptando toda suerte de mitos y sofismas propios del normativismo más burdo. He querido llamar a este fenómeno: el Efecto de la Bifurcación. Digo así, pues entonces se presenta en la mente de quien argumenta una «bifurcación» o separación entre dos esferas: la puramente intelectiva o de comprensión racional, por un lado, y la volitiva o de expresión de la actitud, por el otro. Aquello que cognitivamente se conoce y entiende, empero no se practica. Es como si, valga el símil, la misma persona apareciese en dos canales de televisión distintos: en uno es comentarista de fútbol y en el otro comentarista de cine. Es la misma persona, pero cuando aparece comentando el fútbol, se desvincula y ni siquiera se percate de que en el otro canal está haciendo crítica de cine. El comentarista de fútbol FERRAJOLI conoce las reglas, conoce los equipos, los jugadores y hasta conoce las tácticas y estratagemas que utilizan los entrenadores para salir victoriosos en los partidos; pero cuando se cambia de canal y nos habla sobre el «cine garantista», se olvida de todo aquello y allí describe, no el fútbol real, de las canchas reales y jugadores reales, sino el que se juega en una mesa de plástico, con figuritas de plástico, con una pelota de plástico, ese que los niños conocen como el juego del «futbolito». Y lo más fantástico de todo es que FERRAJOLI insiste en hacernos creer 
que su teoría es «realista» (al menos por una parte), cuando en realidad es una película cercana a la ciencia ficción. Al respecto he indicado, en otro sitio, lo siguiente:

Hay que tener claro, sin embargo, que el mero reconocimiento intelectivo de los sofismas... no es suficiente. Hay una amplia diferencia entre entender una determinada noción e introducirla en la práctica vital e intelectual. Suele suceder (iy es probable que el autor de este texto tampoco escape a ello!) que uno comprende cabalmente el significado o el alcance de un error argumentativo y, sin embargo, llegado el momento, se incurre en el mismo error que se critica. Ello se debe, al menos eso creo, a que la verdadera comprensión de un conocimiento apenas empieza cuando este ha sido realmente internalizado en las estructuras psíquicas, morales e intelectuales, e integrado a la forma cotidiana de ver y valorar el mundo. La superación de los sofismas en la teoría social no es, pues, sólo un asunto de estricta racionalidad. Cuánto una persona luche para superar un hábito depende, en primerísima instancia, de cuánto signifique ese hábito para ella en el plano afectivo y emocional. Cuanto más fuerte sea el significado que una idea tiene para la vida, más fuerte será la resistencia a reconocer la falsedad de dicha idea ${ }^{40}$.

\subsection{Presentar sus ideas bajo unos axiomas básicos que en verdad intervienen ahí como «estrategias de inmunización»}

En todo campo del saber y de la experiencia humana se parte siempre de unos axiomas básicos. Esto es inevitable. Uno no puede construir su posición sobre cimientos colocados en el vacío. No importa si es en la esfera científica o religiosa, física o metafísica, siempre se va a partir de unos puntos de vista que se consideran como fundamentales. A estos puntos de vista se les llama justamente «axiomas», los cuales pueden ser ya sea uno solo o varios compuestos, como base non plus ultra de determinado razonamiento o de determinado edificio teorético en su conjunto. Como el conocimiento no puede retrotraerse indefinidamente, en una suerte de cadena sin límite, entonces algún punto de partida de última instancia (una idea o varias) se hace necesario. Este punto de partida tiene un doble carácter. Por un lado, es ahí el axioma básico, aquello que yo asumo como pre-supuesto de toda la construcción teorética que voy a efectuar. Por otro lado, este punto de partida no es (salvo para mis propios efectos) absoluto; es decir, se trata siempre de unos cimientos que pueden cambiar, con el tiempo y con las circunstancias, por lo cual en este último caso tendré que buscar otro punto de partida. A esta tesis se le conoce técnicamente como falibilismo: aceptar que nuestros conocimientos, y las bases de las que estos parten, pueden estar equivocados y llegar a cambiar. Téngase presente siempre que lo que en un momento se considera como inamovible, ya luego no lo es. Vale decir, no existe lo que en filosofía de la ciencia se ha llamado el punto arquimédico del conocimiento (AlBERT) [recordemos, que ARQUÍMEDES fue el famoso filósofo griego que dijo: «Dadme un punto de apoyo y moveré el mundo». El punto arquimédico sería aquel sobre el cual me apoyo, pero para el cual, a su vez, ya no existe ningún otro apoyo posible: por eso mismo, este punto es axiomático, o en todo caso es «visto» (por parte de quienes lo aceptan) como tal].

De todas maneras, no hay que olvidar que los axiomas, por más básicos que sean para mi propia construcción, son escogidos, o sea, seleccionados por la persona que propone la teoría considerada, o simplemente cuando se hace una afirmación valorati-

${ }^{40}$ M. E. SaLas, Yo me engaño, tú te engañas, él se..., 17. 
va cualquiera. Esa selección puede hacerse consciente o inconscientemente. En la vida cotidiana, casi siempre ello se hace inconscientemente, y entonces uno suele asumir que las otras personas con quienes se hable comparten también esta misma base. Eso permite un diálogo que parcialmente estará libre de gruesas diferencias y contradicciones. Pero también hay oportunidades en que la elección se hace conscientemente: por ejemplo, en el caso del desarrollo de una teoría científica donde se parte de unos presupuestos básicos que se explicitan en el marco teórico de referencia.

Pues bien, ¿qué tiene que ver todo esto con FERRAJOLI y su teoría del garantismo penal? La explicación es esta: también FERRAJOLI parte de unos axiomas (y, dicho sea de paso, él les llama justamente así: «los axiomas del sistema garantista» e incluso habla de un «sistema garantista axiomatizado»). Pero hay que tener claro, sobre todo, que por supuesto esos axiomas elegidos por FERRAJOLI son, jtambién ellos!, únicamente eso: son su elección valorativa. Alguien podría, desde luego, elegir otros «axiomas» de los cuales partir. Esos axiomas que elige FERRAJOLI no son absolutos (¿por qué habrían de serlo?); tampoco se ve por qué tendrían que corresponderse necesariamente con una supuesta «esencia» del derecho penal, ni con una suerte de «naturaleza de las cosas». Ellos son lo que son: unas maneras posibles de valoración ética, política y jurídica, aquellas que el propio FERRAJOLI ha resuelto poner fuera de discusión, las cuales pueden o no ser compartidas por otras personas, ya sea en principio o en cuanto a tales o cuales de sus tipos de aplicaciones prácticas. Empero, salvo que con respecto a esos axiomas y a cuanto FERRAJOLI entienda poder derivar de ellos se adopte sencillamente la posición de «creyente», yo pienso que, al menos en cuanto a sus posibilidades para aplicaciones en la práctica jurídica, el «rendimiento» de tales axiomas debiera ser elucidado (y, si se quiere, defendido) mediante la aportación de razones: presentación de pruebas empíricas y argumentos laicamente plausibles, o sea, siendo ambos de contenido lo bastante intersubjetivo como para acreditarse también por vías de carácter extra-«creyente». Para tales efectos, no se ve cómo pueda servir de mucho el invocar simplemente unas tautologías o unas veleidades semánticas, simplemente sujetas, como criterio supremo de aceptación, a un mero: ¡FERRAJOLI dixit!

Recordemos, nuevamente, que FERRAJOLI estima que los diez axiomas del garantismo penal son los siguientes:
A1 Nulla poena sine crimine.
A2 Nullum crimen sine lege.
A3 Nulla lex (poenalis) sine necesitate.
A4 Nulla necessitas sine iniuria.
A5 Nulla iniuria sine accione.
A6 Nulla actio sine culpa.
A7 Nulla culpa sine indicio.
A8 Nullum iudicium sine accusatione.
A9 Nulla accusatio sine probatione.
A10 Nulla probatio sine defensione.

¿Qué problema veo en todo esto? No que él haya escogido esos axiomas y no otros; por supuesto, siempre hay un derecho de elección. Tampoco, que él quiera formalizarlos en notación de lógica simbólica. Ni lo central de mi crítica se dirige a que 
él defina «Estado de derecho», «garantismo penal», «sistema penal garantista», etc., acudiendo a esos mismos axiomas. Igualmente, uno puede aceptar que FERRAJOLI tiene derecho a construir una teoría de la «legitimación formal y sustancial», de la «validez formal y sustancial», de la «mera legalidad» y de la «estricta legalidad», de la «democracia formal» y la «democracia sustancial», acudiendo a esos mismos axiomas. Todo eso no me parece inaceptable en principio. Sin embargo - y este es el aspecto medular que quiero hacer ver- FERRAJOLI tiene que hacerse responsable por la adopción de justamente esos axiomas. Y por hacerse «responsable» corresponde entender, en este contexto, este término en un sentido muy específico, a saber: la carga intelectual de aceptar no solo los aspectos claros o inequívocos que de dichas ideas se desprendan, sino también sus equívocos y malentendidos. ¡Y vaya que estos axiomas se prestan para malentendidos!

El problema no es, pues, la posibilidad, en abstracto, de construir un dizque sistema garantista sobre la base de algunos enunciados, el problema es más bien definir el carácter que vaya a tener ese sistema y sobre todo sus consecuencias prácticas. Si uno presta atención al catálogo de axiomas adoptado por FERRAJOLI, no tendrá que hacer mucho esfuerzo mental para percatarse de cosas básicas como las siguientes (no digo que todas sean ignoradas por el propio FERRAJOLI):

1. Es un catálogo de cuestiones que ya se conocen desde hace mucho tiempo en el campo del derecho penal. Eso no es nada original o novedoso (creo que FERRAJOLI aceptaría esta afirmación), sino que más bien se trata, en buena lid, de lugares comunes de la teoría del derecho, de la política o de la epistemología jurídica.

2. Es un catálogo de principios muy generales y abstractos en cuanto a su esfera de aplicación o de alcance. Es más, me gustaría decir que se trata, en gran medida, de fórmulas vacías o semivacías (entendiendo por éstas, aquellas expresiones lingüísticas que resultan muy vagas, indeterminadas o polisémicas, tanto en su función lingüística como pragmática). Lo difícil no es postular, si esto viene a ser planteado en términos tan indiscriminadamente generales como lo hace FERRAJOLI, que no hay ley sin una necesidad o necesidad sin un daño. Lo difícil está en saber qué exactamente se vaya a entender ahí por «necesidad»o «daño». Como es bien conocido desde hace décadas en la teoría crítica del derecho, esos dos términos son conceptos jurídicos indeterminados, a los cuales el operador del derecho asigna unos contenidos que van a depender de los valores adoptados, de los fines perseguidos o de las circunstancias del caso concreto, según los intérpretes autorizados. Cuáles valores o fines, o qué interpretaciones al respecto, y aun la selección de cuáles circunstancias se tenga por relevantes, todo esto pueden decidirlo de ciertas maneras unos intérpretes y otros hacerlo de maneras diferentes, en cuanto a los casos individuales o tipos de casos por resolver; dependerá, en la práctica, de las respectivas preferencias ideológicas o en general las concepciones sociales (contingentes) que respectivamente esos intérpretes acojan, entre las diversas consideradas aceptables en su medio social.

3. Es un catálogo básicamente de definiciones persuasivas, entendiendo por éstas, según ya se dijo, unas definiciones en las cuales el elemento emotivo se impone sobre el elemento descriptivo, que es poco o nulo. De allí que, estas máximas sean el condimento preferido de todos los regímenes políticos, no importa si se les llama democráticos o totalitarios, fascistas o garantistas, todos se proclamarán fieles seguidores de éstos u otros principios similares. 
4. Es un catálogo de axiomas que no soluciona problemas concretos, pues «los principios generales no resuelven casos específicos» (HOLMES).

5. Es un catálogo respecto del cual, en virtud de la vaguedad e indeterminación de sus elementos, se pueden «derivar» (así dice FERRAJOLI) muchísimas cosas. Es decir, que es abierto en cuanto a las posibilidad de extraer que de allí otros muchos postulados. El mismo FERRAJOLI sostiene: «En total tendremos cincuenta y seis tesis, diez primitivas y las demás derivadas, que conjuntamente configuran nuestro modelo penal garantista y cognitivo» ${ }^{41}$.

6. Es un catálogo cuyas máximas, efectivamente, están comprendidas en muchas constituciones políticas del mundo. Sin embargo, esas máximas representan, en esencia, muy poco más que un «saludo a la bandera». En la realidad esas máximas son llenadas, por los aplicadores del derecho, con cualquier contenido retórico y terminan justificando cualquier decisión, incluso arbitraria o abiertamente injusta.

\section{CONCLUSIÓN GENERAL}

A lo largo de esta investigación, he presentado una lista de ocho grandes dificultades fundamentales que veo en la obra de FERRAJOLI, específicamente de su libro Derecho y razón, en cuanto al concepto de garantismo penal. Es posible, no lo descarto de antemano, que algunos de esos vicios imputados a FERRAJOLI puedan estar equivocados, que mis observaciones al respecto sean injustas o desproporcionadas para con el autor italiano. Pero me atrevo a aventurar la creencia de que, probablemente, al menos alguno o unos pocos de los «vicios» señalados resulten pertinentes. Que haya dado yo en el blanco y que de esa manera haya contribuido a denunciar al menos algunos malentendidos propios de esa nebulosa doctrina, me parece que debería merecer alguna reflexión, sobre todo por partidarios («creyentes») de ella. ¡Ojalá que así sea!

He tratado, en todo mi recorrido, de ofrecer argumentos y evidencias contra las tesis de FERRAJOLI. Es obvio que contra FERRAJOLI mismo, su persona en la vida real, no tengo nada; eso debiera haber quedado más que suficientemente claro, pues me he referido nada más a su desempeño como teórico. Empero, sean cuales fueren sus intenciones subjetivas personalísimas (y ciertamente no tengo por qué dudar de que no sean las mejores), sí creo que su doctrina ha contribuido, ¡de hecho!, más bien a que se retroceda en el ámbito del derecho penal. Ella sirve, directa o indirectamente, con o sin la suscripción de su creador, para alejar la mirada de las cuestiones fundamentales y controvertidas que acechan actualmente en la experiencia misma del derecho penal. Cuestiones controvertidas que no se atacan a fuerza de tambor y humo, como quien quiere asustar los coyotes que aúllan amenazantes en el pastizal, sino que hay que prenderles fuego; es decir, combatirlas con medidas concretas, o al menos presentar estas mismas a la consideración pública especificándolas como tales. A la fecha, siguen en la sala de espera. Y, por cierto, FERRAJOLI no ha contribuido a elaborar nada por el estilo, sino que antes bien su obra contribuye a apartar la mirada de tales cuestiones, las verdaderamente prácticas, desviándola hacia cierta región de inofensivos discursos sobre unas impolutas abstracciones tranquilamente librescas.

\footnotetext{
${ }^{41}$ L. FerRajoli, Derecho y razón, 94.
} 
Por eso, terminaré este ensayo con un ad hominem (soy bien consciente de que es tal) y con una pequeña dosis de humor. Hace algún tiempo, HABA publicó un artículo en alemán ${ }^{42}$, donde acuñó el feliz término: la «Santa (Charla) Familia» [die Heilige (Rede-)Familie], para referirse a cierto tipo de discursos teoréticos desempeñados en círculos académicos para ocuparse de la llamada Razón Práctica, teorizaciones que van en dirección esencialmente retórica. Se trata de la producción discursiva propiciada por unos autores muy conocidos, de moda en el ámbito internacional de la filosofía del derecho - HABERMAS, RAWLS, ALEXY, DWORKIN—, a quienes más tarde él calificó (en otro sitio), con justeza creo yo, de Scholar-Dreammakers. Pues bien, después de lo indicado en las páginas precedentes, y habiendo examinado las tesis básicas del garantismo penal bajo la luz de una visión crítica y realista, propongo la moción de que a L. FERRAJOLI se le incorpore, con muchísimos méritos, a la plantilla oficial de la «Santa (Charla) Familia». Y que en adelante se le otorgue el grado, summa cum laude de:

\section{¡Doctor Dreammaker en derecho penal!}

\section{APÉNDICE. LOS SENTIDOS DE «GARANTISMO»}

Ofrezco aquí una caracterización más detallada de lo que FERRAJOLI entiende por «garantismo»y, específicamente, por «garantismo penal». Voy a transcribir algunos pasajes suyos típicos al respecto (incluso unos que son algo extensos).Ya sabemos que estos catálogos de definiciones no solo están desprovistos de mayores efectos prácticos, sino que tampoco aportan conocimiento sustantivo alguno (salvo sobre ellas mismas, en sí mismas y por sí mismas). Por lo demás, esto puede resultar aburrido y como forma de estilo literario no es, sin duda, la mejor. Sea como fuere, aquí ello obedece únicamente a que yo no quisiera dar lugar, en modo alguno, a suponer que pongo en boca de FERRAJOli, o en su cabeza, cosas que él no haya dicho expresamente; de ahí que, si el lector está interesado en esta muestra de escolasticismos, no tendrá más remedio que armarse de la necesaria paciencia para poder seguirlos. Paso a dejar consignada, pues, una síntesis de las ideas centrales, con la esperanza de que esto resulte suficientemente indicativo al respecto.

¿Qué entiende FERRAJOLI por «garantismo» y, más concretamente, por garantismo penal? Ya se mencionó en la presentación de este trabajo que, en la actualidad y a la luz de la divulgación internacional del garantismo, ese concepto se ha convertido, poco más o menos, que en una fórmula vacía (Leerformeln $)^{43}$ de tipo emocional, pues ella se utiliza en los más variados contextos y con propósitos casi siempre persuasivos. De cara a esa tendencia, nuestro autor ha intentado dar un contenido más preciso a

42 E. P. HABA, «Standortbestimmung zeitgenössischer Rechtstheorie - Rawls, Dworkin, Habermas und andere Mitglieder der "Heiligen (Rede-)Familie"», en: Rechtstheorie, vol. 27, cuaderno 3, Berlin, Duncker \& Humblot, 1998, 237-277. Buena parte de ese trabajo se encuentra traducida al español en el estudio del mismo autor: «Contra la "Santa (charla-) Familia". Anclajes básicos de la vocación astronáutica promovida por Rawls, Habermas y otros apóstoles del wishful thinking académico», Doxa, 30 (2007), 491-524.

${ }_{43}$ Vid., al respecto, mi trabajo Yo me engaño, tú te engañas, él se..., en especial el capítulo II «El sofisma de la magia verbal y del naturalismo lingüístico», 59 y ss. 
tal categoría. Son varios los sitios en los cuales podría rastrearse una definición de garantismo. Conformémonos con examinar algunas de esas definiciones. Uno de los más representativos intentos por precisar la categoría del garantismo es un estudio suyo publicado en la revista italiana Parolechiave, donde ofrece la siguiente caracterización:

En general, se hablará de garantismo para designar el conjunto de límites y vínculos impuestos a todos los poderes - públicos y privados, políticos (o de mayoría) y económicos (o de mercado), en el plano estatal y en el internacional- mediante los que se tutelan, a través de su sometimiento a la ley y, en concreto, a los derechos fundamentales en ella establecidos, tanto las esferas privadas frente a los poderes públicos, como las esferas públicas frente a los poderes privados ${ }^{44}$.

Después él define, a partir de esa determinación general, el garantismo penal como el conjunto de:

[T]écnicas de defensa de los derechos de libertad y, entre ellos, en primer lugar, el de la libertad personal, frente a las intervenciones arbitrarias de tipo policial o judicial... ${ }^{45}$.

Ahora bien, esta caracterización general del garantismo, en primer lugar, y del garantismo penal, en segundo lugar, no da cuenta (y en eso hay que ser muy francos) de la complejidad del concepto elaborado por FERRAJOLI a lo largo de su vasta obra ${ }^{46}$. Lo fundamental se ubica, más allá de una mera definición nominal sobre una categoría de análisis, en los elementos que la componen y que forman su esqueleto conceptual. Con la meta de examinar justamente estos elementos, a continuación voy exponer con más detalle lo expresado a ese respecto por el autor.

\subsection{Garantismo en sentido general}

La noción de garantismo - que en un primer momento podemos llamar simplemente «general»- presupone al menos tres niveles distintos. Vale la pena explicarlos separadamente, pues constituyen la base de la estructura arquitectónica del edificio garantista ${ }^{47}$.

a) En primer lugar, el garantismo es un modelo normativo de derecho que se caracteriza por el apego a la «legalidad estricta» (stretta legalità); y esta, a diferencia de la legalidad en sentido amplio, exige — según FERRAJOLI- que la ley condicione determinados contenidos sustanciales. Es decir, que no sólo basta, para que una norma sea válida, la promulgación por parte de instancias competentes y de acuerdo con unos ciertos procedimientos (el quién y el cómo), sino que también ha de prestarse especial

${ }_{44}$ Ese estudio se recoge en su versión castellana en FERRAJOLI, «Garantías», 40.

${ }^{45} \mathrm{Id}$.

46 El autor desarrolla, en primer lugar, una definición del garantismo penal basada en tres niveles (que seguidamente se expondrá), para luego incursionar en una teoría general del garantismo: «Estas tres acepciones de "garantismo", de las que hasta aquí he proporcionado una connotación solamente penal, tienen a mi juicio un alcance teórico y filosófico general que merece ser explicado. Delinean, efectivamente, los elementos de una teoría general del garantismo...»: Derecho y razón, 854.

${ }_{47}$ Cfr. el artículo «El modelo garantista de Luigi Ferrajoli. Lineamientos generales», de R. MORENO CRUZ, publicado en Boletín Mexicano de Derecho Comparado, nueva serie, año XL, núm. 120, septiembrediciembre de 2007. 
cuidado al contenido (al qué de la norma). Esta distinción da pie a dos tipos de legitimación: legitimación formal y legitimación sustancial; ello está gobernado, a su vez, por una racionalidad formal y una sustancial. Así, el modelo o sistema garantista:

...no programa solamente sus formas de producción a través de normas de procedimiento sobre la formación de las leyes y demás disposiciones. Programa además sus contenidos sustanciales, vinculándolos normativamente a los principios y a los valores inscritos en sus constituciones, mediante técnicas de garantía cuya elaboración es tarea y responsabilidad de la cultura jurídica ${ }^{48}$.

Las distinciones realizadas por FERRAJOLI apuntan, en realidad, a dos conceptos que resultan fundamentales en el presente contexto. Dichos conceptos son el de validez en sentido formal (vigencia) y validez en sentido material (o validez propiamente dicha):

En efecto, la existencia de normas inválidas puede ser fácilmente explicada con sólo distinguir dos dimensiones de la regularidad o legitimidad de las normas: la que se puede llamar «vigencia» o «existencia», que hace referencia a la forma de los actos normativos y que depende de la conformidad o correspondencia con las normas formales sobre su formación; y la «validez» propiamente dicha o, si se trata de leyes, la «constitucionalidad», que, por el contrario tiene que ver con sus significado o contenido y que depende de la coherencia con las normas sustanciales sobre su producción ${ }^{49}$.

Como modelo de derecho, el garantismo presupone la existencia de dos nociones fundamentales: la de un Estado de derecho (stato di diritto) y la de una democracia.

- Se va a entender el Estado de derecho como aquel donde existe: o bien, un gobierno sub lege, o sea, sometido a las leyes; o bien, aquel donde hay un gobierno per leges, o sea, dominado mediante leyes generales y abstractas. Estas dos nociones del Estado de derecho se deben asociar, a su vez, con dos conceptos claves para FERRAJOLI: por un lado, el de validez formal, que exige únicamente una definición de las formas en que se ejerce el poder y de qué sujetos sean los titulares de ese poder; por otro lado, el concepto de validez material, el cual exige adicionalmente que estén claramente definidas las materias de competencia y los criterios de decisión. Esto da pie a distinguir entre una legitimación formal, por un lado, y una legitimación material, por el otro; o dicho en otros términos, entre una legalidad en sentido amplio y una legalidad en sentido estricto. Todos estos conceptos se materializan, a su vez, en dos formas distintas de Estado: el Estado de derecho liberal, con sus respectivas garantías liberales negativas; y el Estado de derecho social, con sus garantías sociales positivas $^{50}$.

48 L. FERRAJOLI, «Garantías», 63.

${ }^{49}$ L. FERRAJOLI, «El derecho como sistema de garantías», en Jueces para la democracia, núms. 16-17, Madrid, 1992, 64.

${ }^{50}$ Con palabras de FerRAJOLI, el Estado de derecho se caracteriza por: «a) en el plano formal, por el principio de legalidad, en virtud del cual todo poder público — legislativo, judicial y administrativo— está subordinado a leyes generales y abstractas, que disciplinan sus formas de ejercicio y cuya observancia se halla sometida a control de legitimidad por parte de jueces separados del mismo e independientes...; $b$ ) en el plano sustancial, por la funcionalización de todos los poderes del estado al servicio de la garantía de los derechos fundamentales de los ciudadanos, mediante la incorporación limitativa en su Constitución de los deberes públicos correspondientes, es decir, de las prohibiciones de lesionar los derechos de libertad y de las obligaciones de dar satisfacción a los derechos sociales, así como los correlativos poderes de los ciudadanos de activar la tutela judicial», Derecho y razón, 856-857. 
- Respecto a la noción de democracia, hay que tener claro que para FerRAJOLI el Estado de derecho, como conjunto de las garantías liberales y sociales, equivale a democracia, pero no entendida en sentido formal, sino sustancial.

[E]n un sentido no formal y político sino sustancial y social de «democracia», el estado de derecho equivale a la democracia: en el sentido de que refleja, más allá de la voluntad de la mayoría, los intereses y las necesidades vitales de todos ${ }^{51}$.

b) En su segunda acepción, el garantismo designa una teoría jurídica que mantiene separados el plano del ser y del deber ser, proponiendo como cuestión central la distancia que opera entre el plano normativo y el práctico. FERRAJOLI habla, por eso, del garantismo como una teoría de la divergencia entre normatividad y realidad, entre derecho válido y derecho efectivo. Alude a que una teoría garantista del derecho penal ha de ser normativista y realista al mismo tiempo:

La desarrollada en este libro es, por ejemplo, una teoría garantista del derecho penal normativista y realista al mismo tiempo: referida al funcionamiento efectivo del ordenamiento tal y como se expresa en sus niveles más bajos, sirve para revelar sus rasgos de validez y sobre todo de invalidez; referida a los modelos normativos tal y como se expresan en sus niveles más altos, es idónea para revelar su grado de efectividad y, sobre todo, de inefectividad. Bajo ambos aspectos el garantismo opera como doctrina jurídica de legitimación y sobre todo de deslegitimación interna del derecho penal, que reclama de los jueces y de los juristas una constante tensión crítica hacia las leyes vigentes... ${ }^{52}$.

Como teoría del derecho, el garantismo surge dentro del «positivismo jurídico», según FERRAJOLI, y busca básicamente una crítica y deslegitimación interna de las normas vigentes inválidas. Empero, el autor distingue entre dos formas de positivismo: el que denomina crítico y el dogmático. Este último consiste, básicamente, en una orientación teórica que ignora el concepto de vigencia de las normas como independiente de la validez y efectividad de éstas. Por su parte, el autor se suma a una forma de iuspositivismo crítico que:

...se configura sobre todo como crítica del derecho positivo vigente no meramente externa, política o de iure condendo, sino interna, jurídica o de iure condito, puesto que va dirigida a aspectos de inefectividad y de invalidez. Este planteamiento, que bien podemos llamar «positivismo crítico», se refleja en el modo de concebir el trabajo del juez y del jurista, y pone en cuestión dos dogmas del positivismo dogmático: la fidelidad del juez a la ley y la función meramente descriptiva y avalorativa del jurista en relación con el derecho positivo vigente $^{53}$.

c) En su tercera acepción, el garantismo no significa ya sólo un modelo normativo y una teoría del derecho, sino también, y en términos generales, una filosofía política que impone al derecho y al Estado la necesidad de una justificación externa de su accionar. Dentro de esta filosofía política introduce FERRAJOLI un concepto que, al parecer, se presenta como fundamental en el marco de su sistema garantista. Me refiero a la llamada esfera de lo indecidible ${ }^{54}$. Dice él:

51 L. FERRAJOLI, Derecho y razón, 864.

52 Ibid., 853.

53 Ibid., 872.

54 FERRAJOLI tiene un trabajo específico sobre esta categoría de análisis: «La esfera de lo indecidible y la división de poderes», publicado en Estudios Constitucionales, año 6, núm. 1, Centro de Estudios Constitucionales de Chile, Universidad de Talca, 2008, 337 y ss. 
He utilizado en otras ocasiones la expresión «esfera de lo indecidible» para denominar al conjunto de principios que, en democracia, están sustraídos a la voluntad de las mayorías $^{55}$.

Como una filosofía política, el garantismo permite la crítica y la deslegitimación, externamente, de las instituciones jurídicas positivas, por ser entonces conforme a una separación estricta entre derecho y moral. Apropiándose del concepto luhmanniano, FERRAJOLI distingue entre dos tipos de doctrinas políticas: las auto-poyéticas y las hétero-poyéticas.

Para las doctrinas auto-poyéticas, el estado es un fin y encarna valores ético-políticos de carácter supra-social, supra-individual a cuya conservación y reforzamiento han de instrumentalizarse el derecho y los derechos. Para las doctrinas hétero-poyéticas, por el contrario, el estado es un medio legitimado únicamente por el fin de garantizar los derechos fundamentales de los ciudadanos, y políticamente ilegítimo si no los garantiza o, más aun, si él mismo los viola ${ }^{56}$.

Desde esta perspectiva, como filosofía política, el garantismo es una doctrina hétero-poyética, donde se niega una legitimación «desde arriba» del derecho, sea desde fuentes suprahistóricas, metafísicas o metahistóricas: Dios, la naturaleza, la religión. Por el contrario, la legitimación es siempre externa o «desde abajo»; es decir, de la sociedad misma como suma de personas, intereses y clases sociales.

$$
* * *
$$

Ahora bien, una lectura de lo señalado hasta este punto, dará cuenta de que lo expuesto por FERRAJOLI no atañe, al menos de manera inmediata, sólo al campo jurídico penal, sino que cubre áreas tan vastas como el derecho constitucional y los derechos fundamentales. En lo relativo al campo penal, en sentido estricto, es más difícil determinar cuál sería una opinión o algún parecer puntual de nuestro autor sobre qué ha de significar allí el término garantismo. Empero, esto no es impedimento para que, desde diferentes capítulos o apartados del libro Derecho y razón, uno pueda reconocer elementos claves de la teoría garantista propuesta allí y en función de esos conseguir delinear también los contornos básicos de un concepto propio para ese campo específico.

\subsection{Garantismo en sentido penal}

Según FERRAJOLI, se puede denominar garantista, o también cognitivo o de estricta legalidad, a un sistema de derecho penal cuando comprende una serie de principios o máximas fundamentales. Él piensa que existen diez máximas (o axiomas) que dan pie a toda la estructura garantista en el derecho penal: A1 Nulla poena sine crimine. A2 Nullum crimen sine lege. A3 Nulla lex (poenalis) sine necessitate. A4 Nulla necessitas sine iniuria. A5 Nulla iniuria sine actione. A6 Nulla actio sine culpa. A7 Nulla culpa sine iudicio. A8 Nullum iudicium sine accusatione. A9 Nulla accusatio sine probatione. A10 Nulla probatio sine defensione. Según la opinión expresa de FERRAJOLI: «Estos diez principios, ordenados y conectados aquí sistemáticamente, definen — con cierto

\footnotetext{
55 Ibid., 337.

56 L. FERRAJOLI, Derecho y razón, 881.
} 
forzamiento lingüístico - el modelo garantista de derecho o responsabilidad penal, esto es, las reglas del juego fundamentales del derecho penal» ${ }^{57}$. Estima, además, que esos diez axiomas se encuentran encadenados de tal suerte que «cada uno de los términos implicados impli[ca] a su vez al sucesivo» ${ }^{58}$.

En cuanto a la funcionalidad o no de este modelo axiomático de principios, FERRAJOLI es claro al sostener que ellos (los principios) «valen también para garantizar la inmunidad de los ciudadanos respecto de intervenciones punitivas infundadas o arbitrarias, este modelo de responsabilidad penal no es sólo un modelo epistemológico de racionalidad del juicio, sino también un modelo regulativo de justicia formal» ${ }^{59}$. De estas consideraciones de tipo epistemológico — por un lado- y jurídico-penales - por el otro-, colige FERRAJOLI otra definición posible de lo que ha de entenderse por garantismo:

El garantismo penal es ante todo un modelo cognoscitivo de identificación de la desviación punible basado en una epistemología convencionalista y refutacionista (o falsacionista) hecha posible por los principios de estricta legalidad y de estricta jurisdiccionalidad ${ }^{60}$.

Adicionalmente, en el sistema garantista ejerce una especial importancia la posibilidad de que las decisiones se adopten de una manera racional, esto es, sean cognitivamente legítimas. Aquí FeRRAJOLI propone dos modelos epistemológicos judiciales contrapuestos: cognoscitivismo y decisionismo ${ }^{61}$. El cognoscitivismo se ampara en la verificación (fáctica) de los hechos, en la búsqueda de la verdad, en la comprobación de los supuestos que dan pie a una acusación; estando consciente, por supuesto, de que todo ello opera en el derecho penal (y procesal penal) de una manera aproximativa. De allí que: «La función judicial, y particularmente la penal, difiere conforme a ello de todas las demás funciones del estado porque es una actividad cognoscitiva, donde las elecciones y las decisiones vienen justificadas por criterios pragmáticos y subjetivos pero siempre referidos, como en cualquier otra forma de conocimiento, a la búsqueda de la verdad objetiva» ${ }^{62}$.

$$
* * *
$$

En resumen: de acuerdo con las consideraciones expuestas, estimo que resulta bastante claro que en el sistema ferrajoliano hay, al menos, dos niveles distintos en la comprensión de lo que ha de entenderse por «garantismo»: a) un nivel general, propio del derecho constitucional y de los derechos fundamentales, donde el concepto de garantismo consiste en una categoría de tres niveles: como un modelo normativo, como una teoría jurídica y como una filosofía política; $b$ ) un nivel estrictamente jurídicopenal, asentado en una serie de principios, máximas y axiomas, todo lo cual genera, a su vez, una epistemología cognoscitiva y una decisionista.

57 Ibid., 93.

58 Ibid., 94.

59 Ibid., 97.

60 Ibid., 169.

61 Ibid., cap. 1.

62 Ibid., p. 69. Hace FerRajoli la salvedad de que la «verdad» del derecho penal es una «verdad-poder», en tanto implica una decisión práctica (o sea, una sentencia de absolución o de condena). 